\title{
Elimination of 01/A'-A0 pre-rRNA processing by-product in human cells involves cooperative action of two nuclear exosome-associated nucleases: RRP6 and DIS3
}

\author{
KAMIL KOBYKECKI, ${ }^{1,2}$ KAROLINA DRĄŻKOWSKA, ${ }^{3}$ TOMASZ M. KULIŃSKI, ${ }^{1,2}$ ANDRZEJ DZIEMBOWSKI, ${ }^{1,2}$ \\ and RAFAK TOMECKI ${ }^{1,2}$ \\ ${ }^{1}$ Laboratory of RNA Biology and Functional Genomics, Institute of Biochemistry and Biophysics, Polish Academy of Sciences, 02-106 Warsaw, \\ Poland \\ ${ }^{2}$ Department of Genetics and Biotechnology, Faculty of Biology, University of Warsaw, 02-106 Warsaw, Poland \\ ${ }^{3}$ Department of RNA Metabolism, Institute of Bioorganic Chemistry, Polish Academy of Sciences, 61-704 Poznan, Poland
}

\begin{abstract}
Pre-rRNA processing generates mature $18 \mathrm{~S}, 5.8 \mathrm{~S}$, and $28 \mathrm{~S} / 25 \mathrm{~S}$ rRNAs through multistage removal of surrounding $5^{\prime}$-ETS/ $3^{\prime}$-ETS and intervening ITS1/ITS2 segments. Endonucleolytic activities release by-products, which need to be eliminated. Here, we investigated the interplay of exosome-associated $3^{\prime}-5^{\prime}$ exonucleases DIS3 and RRP6 in rRNA processing and by-product elimination in human cells. In agreement with previous reports, we observed accumulation of $5.8 \mathrm{~S}$ and $18 \mathrm{~S}$ precursors upon dysfunction of these enzymes. However, none of these phenotypes was so pronounced as previously overlooked accumulation of short RNA species derived from $5^{\prime}$-ETS $\left(01 / A^{\prime}-A 0\right)$, in cells with nonfunctional DIS3. We demonstrate that removal of $01 / A^{\prime}-A 0$ is independent of the XRN2 5'-3' exonucleolytic activity. Instead, it proceeds rapidly after $A 0$ cleavage and occurs exclusively in the $3^{\prime}-5^{\prime}$ direction in several phases-following initiation by an unknown nuclease, the decay is executed by RRP6 with some contribution of DIS3, whereas the ultimate phase involves predominantly DIS3. Our data shed new light onto the role of human exosome in $5^{\prime}$-ETS removal. Furthermore, although $01 / A^{\prime}-$ $\mathrm{AO}$ degradation involves the action of two nucleases associated with the exosome ring, similarly to $5.8 \mathrm{~S} 3^{\prime}$-end maturation, it is likely that contrary to the latter process, RRP6 acts prior to or redundantly with DIS3.
\end{abstract}

Keywords: pre-rRNA processing; exosome; DIS3; RRP6; XRN2

\section{INTRODUCTION}

The RNA exosome is a macromolecular assembly involved in the majority of RNA metabolic processes both in the nucleus and in the cytoplasm of eukaryotic cells (Kilchert et al. 2016; Łabno et al. 2016a; Zinder and Lima 2017). Initially discovered in Saccharomyces cerevisiae as a machinery participating in the processing of ribosomal RNA precursor molecules (Mitchell et al. 1997), the exosome complex has been later demonstrated to act as a factor critical for maturation, degradation, and quality control of various RNA classes in yeast and higher eukaryotes, including humans.

Independent structural studies revealed that the eukaryotic exosome comprises a barrel-shaped nine-subunit ring with an inner channel (Bonneau et al. 2009; Malet et al. 2010; Makino et al. 2013, 2015; Zinder et al. 2016). Although the ring is catalytically inert in yeast and humans,

Corresponding author: rtom1916@gmail.com

Article is online at http://www.rnajournal.org/cgi/doi/10.1261/rna. 066589.118. the exosome channel considerably influences enzymatic activities coming from nuclease subunits associated with the ring (Dziembowski et al. 2007; Wasmuth and Lima 2012; Drazkowska et al. 2013). The yeast nuclear exosome encompasses two 3'-5' exoribonucleases interacting with the ring: Dis3 and Rrp6 (Briggs et al. 1998; Burkard and Butler 2000; Dziembowski et al. 2007). In addition, an Nterminal Dis3 PIN domain displays endoribonuclease activity (Lebreton et al. 2008; Schaeffer et al. 2009; Schneider et al. 2009). There are some variations in the composition of exosomes present in the nucleus and cytoplasm of human cells compared to $S$. cerevisiae (Lykke-Andersen et al. 2011). Nevertheless, human nuclear complex contains DIS3 and RRP6 proteins homologous to yeast nucleases (Tomecki et al. 2010).

(C) 2018 Kobyłecki et al. This article is distributed exclusively by the RNA Society for the first 12 months after the full-issue publication date (see http://rnajournal.cshlp.org/site/misc/terms.xhtml). After 12 months, it is available under a Creative Commons License (Attribution-NonCommercial 4.0 International), as described at http:// creativecommons.org/licenses/by-nc/4.0/. 
Pre-rRNA processing is one of the key phenomena, the correctness of which ensures proper ribosome biogenesis in eukaryotes. 18S, 5.8S, and $28 \mathrm{~S}$ mature ribosome RNAs are released from a large polycistronic precursor in a complex series of endonucleolytic cleavage events and exonucleolytic trimming reactions, catalyzed by a wide variety of nucleolytic enzymes (for review, see Tomecki et al. 2017; see Fig. 1A,B for illustration of this process in human cells). The details of pre-rRNA processing pathways differ between taxa. This is mainly because the processing sites are located in the primary transcript spacer regions referred to as 5'-ETS, 3'-ETS and ITS1, ITS2, surrounding and separating mature rRNA segments, respectively, which are highly divergent between organisms so evolutionarily distant as yeast and humans (Tomecki et al. 2017). Furthermore, since spacers are considerably longer in human pre-rRNA compared to yeast, some additional processing sites are present only in the former, but not the latter, species (Tomecki et al. 2017).

A vital process, which occurs concurrently with rRNA maturation, is removal of spacer fragments generated after endonucleolytic cleavages of pre-rRNA (Tomecki et al. 2017). Due to the high level of rDNA transcription, significant amounts of such by-products arise during processing, and their excessive accumulation may adversely affect cellular homeostasis. In addition, inefficient or improper processing can lead to the appearance of aberrant prerRNA intermediates, which should be likewise eliminated from the cell. rRNA quality control is exerted primarily by $5^{\prime}-3^{\prime}$ and $3^{\prime}-5^{\prime}$ exoribonucleases such as XRN family of enzymes and the exosome, respectively (Fig. 1C).

In yeast, most rRNA processing by-products, including $A_{0}-A_{1}, A_{2}-A_{3}$, and $A_{3}-B_{1 L}$ are degraded in the nucleus by Rat1 and its close homolog, Xrn1, in the 5'-3' direction. Furthermore, Xrn1 removes D-A fragment in the cytoplasm (Fig. 1D; Petfalski et al. 1998). Similarly, vertebrate $A 0-1 / A 1$ and $E / 2 a-2$ fragments, equivalent to $S$. cerevisiae $A_{0}-A_{1}$ and $A_{2}-A_{3}$, respectively, and unique $5^{\prime}-01 / A^{\prime}$ as well as $4 a-4$ intermediates, are removed by Rat1 orthologue, XRN2 (Fig. 1C; Wang and Pestov 2011; Sloan et al. 2013, 2014; Memet et al. 2017). Members of the XRN family of nucleases are also involved in the maturation of the 5 '-ends of 5.8S and 25/28S rRNAs in both yeast and mammalian cells (Henry et al. 1994; Petfalski et al. 1998; Preti et al. 2013).

The most thoroughly characterized function of the exosome in ribosomal RNA maturation, involving exo- and endoribonucleolytic activities of DIS3 and RRP6 exoribonuclease in yeast and humans, is the processing of $3^{\prime}$-extended 5.8S precursors. This process has been largely studied in vivo (Mitchell et al. 1996; Briggs et al. 1998; Allmang et al. 1999, 2000; Lebreton et al. 2008; Tafforeau et al. 2013; Tomecki et al. 2014), but recent structural investigations and in vitro reconstitution provided more detailed mechanistic insights (Bonneau et al. 2009; Makino et al. 2015; Fromm et al. 2017; Schuller et al. 2018). 5.8S
rRNA 3 '-end maturation requires sequential action of both exosome-associated nucleases. Longer $7 \mathrm{~S}$ precursors are first threaded via the exosome channel to the exonuclease active site of DIS3, located at the bottom of the ring. This generates shorter $5.8 \mathrm{~S}+30-40$ nt intermediates, which cannot access DIS3 anymore due to the well-described structural constraints and are thus handed-over for further trimming to the catalytic center of RRP6, situated on top of the ring. Human RRP6 is also responsible for the major pathway of the 18S rRNA 3 '-end maturation (Preti et al. 2013; Sloan et al. 2013). All catalytic activities of the yeast nuclear exosome contribute to the removal of $+1-A_{0}$ processing intermediate derived from the $5^{\prime}$ ETS (Fig. 1D; Lebreton et al. 2008). siRNA-mediated depletion of mouse or human RRP6 led to the accumulation of 01/A'-A0 5'-ETS fragment, reversed by expression of wild-type RRP6, but not a catalytically dead variant of this protein, indicating that degradation of $5^{\prime}$-proximal fragments generated by cleavage at corresponding sites $A_{0} / A 0$ is an RRP6 function conserved across eukaryotic lineage (Kent et al. 2009; Sloan et al. 2014). On the contrary, the involvement of DIS3 nuclease activities in the elimination of processing by-products excised from rRNA precursors in human cells has not been demonstrated so far. Results of RNAi experiments performed by others, together with the apparent exclusion of DIS3 from nucleoli of human cells that we observed previously (Tomecki et al. 2010; Sloan et al. 2013, 2014), suggested that DIS3 rather does not play a role in this process.

Here, we investigated degradation of the $5^{\prime}$-ETS 01/A'AO by-product in human cells. We demonstrate that it is probably initially trimmed at the 3 '-end by an unkown enzyme, and subsequently eliminated by both nuclease subunits of the exosome-RRP6 and DIS3-in a collaborative manner, in a two-stage process, where RRP6 activity likely precedes that of DIS3. This is opposed to 7S rRNA, a wellknown exosome substrate in the 5.8S rRNA $3^{\prime}$-end maturation pathway.

\section{RESULTS AND DISCUSSION}

\section{Catalytic mutations in DIS3, but not RRP6, diminish de novo rRNA synthesis, however the overall ribosome biogenesis is not substantially affected}

The involvement of the exosome nucleolytic activities in rRNA maturation in human cells has not been systematically studied to date, apart from demonstrating the participation of DIS3 and RRP6 in the processing of 5.8S and 18S rRNA 3'-ends, respectively (Tomecki et al. 2010, 2014; Preti et al. 2013; Sloan et al. 2013; Tafforeau et al. 2013; Szczepińska et al. 2015). To address this problem more accurately, we used a previously established cellular model, in which the expression of endogenous gene coding for either DIS3 or RRP6 was silenced by sh-miRNAs (artificial 


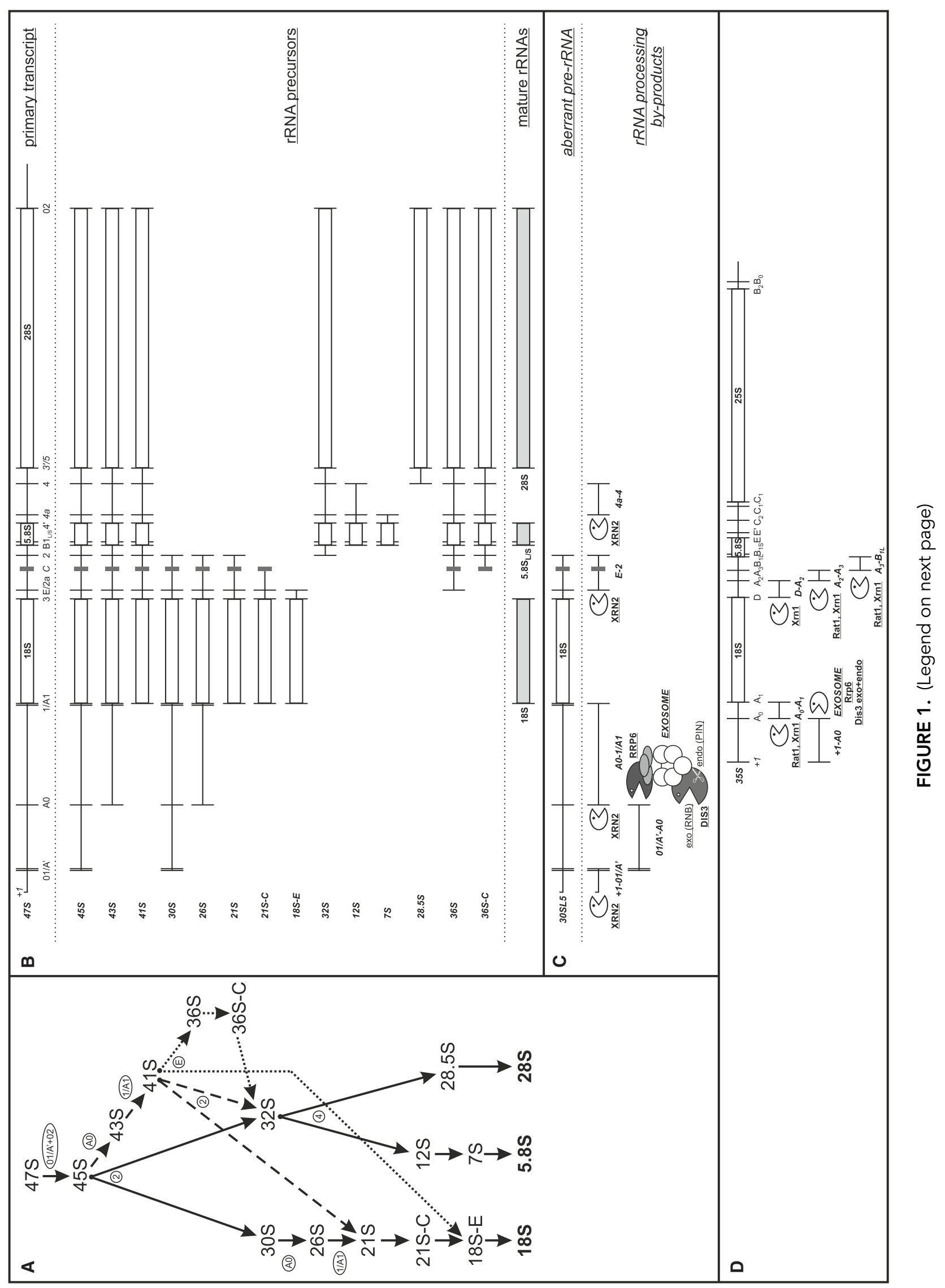


miRNAs $100 \%$ homologous to the target sequence, expressed from genomically integrated construct and processed via miRNA pathway), and simultaneously, wildtype protein or its counterpart with catalytic mutation(s) was produced from exogenous transcript, insensitive to sh-miRNA action (Fig. 2A).

We aimed at directly comparing phenomena associated with pre-rRNA processing between six different cell lines: four producing one of the DIS3 variants (wild-type, WT; mutant of the RNB exonuclease domain, RNB MUT; mutant of the PIN endonuclease domain, PIN MUT; or mutant of both catalytic domains, DM) and two producing one of the RRP6 versions (WT or mutant of the DEDD exonuclease domain, mut). Therefore, it was essential to quantitatively estimate degrees of endogenous wild-type DIS3 or RRP6 depletion, as well as to assess whether similar amounts of different exogenous variants of exosome nucleases are produced, and what is the level of their expression compared to respective endogenous proteins. Western blot quantification of endogenous DIS3 and RRP6 depletion at the protein level was technically impossible due to the small molecular weight difference ( $<1 \mathrm{kDa}$ ) between FLAG-tagged exogenous and untagged endogenous proteins. Thus, to verify silencing efficiency at the mRNA level, quantitative RTPCR was performed using primers specific to endogenous transcripts coding for proteins under investigation. This quantitative analysis showed that, relative to parental Hek293 Flp-In T-REx cells, around 80\%-90\% down-regulation of both DIS3 and RRP6 mRNAs was achieved upon shmiRNA induction in respective model cell lines (Fig. 2B). In order to compare amounts of different DIS3 or RRP6 variants and to check levels of their expression with regard to endogenous proteins in established model cell lines, western blot analyses were performed. Using anti-FLAG antibodies, we demonstrated that all four DIS3 variants and two RRP6 variants were efficiently produced in respective cell lines (Fig. 2C). Importantly, wild-type and mutant variants of either protein were expressed at approximately the same levels, as also documented by immunoblotting with anti-DIS3 and anti-RRP6 antibodies (Fig. 2C). Moreover, ex- ogenous RRP6 variants were not overexpressed, whereas the levels of exogenous DIS3 variants were $~ 5-10 \times$ higher compared to endogenous DIS3 (Fig. 2C,D). This degree of overexpression is rather moderate taking into account the properties of the cell system utilized, and is difficult to avoid, nevertheless it does not preclude drawing biologically relevant conclusions, as demonstrated by our previous findings concerning various human proteins, including DIS3 (Tomecki et al. 2014, 2015; Szczepińska et al. 2015; Łabno et al. 2016b).

RNA exosome complex is undoubtedly a vital ribosome biogenesis factor, playing roles in rRNA maturation and elimination of pre-rRNA processing by-products in all eukaryotes. However, it has never been investigated whether exosome catalytic dysfunction in human cells impedes overall rRNA or ribosome synthesis. Therefore, to monitor possible differences in de novo ribosomal RNA synthesis between model cell lines, pulse-chase metabolic RNA labeling with radioactive phosphate was performed (Fig. $2 E, F)$. This analysis showed that mutation in the DIS3 RNB domain, particularly in combination with a mutation in the PIN domain, reduces amounts of newly synthesized rRNA molecules. This is likely due to the previously reported synergistic negative effect of combined mutations within DIS3 endo- and exonuclease domains on cell growth rate and metabolic activity (Tomecki et al. 2014). Based on the same model cell lines as used herein, we previously noted that expression of catalytically compromised DIS3 leads to significant changes in the noncoding transcriptome and deregulation of expression of around $50 \%$ mRNAs coding for proteins (Szczepinska et al. 2015). It is very difficult at this stage to determine cause-and-effect relationships between molecular phenotypes resulting from DIS3 enzymatic dysfunction, which affects various classes of transcripts, but it must be taken into account that diminished rRNA synthesis is a secondary effect of these global transcriptome changes.

Contrary to DIS3, a catalytic mutation in RRP6 did not affect rRNA synthesis (Fig. 2E,F). It cannot be formally excluded that this could be due to near-physiological

FIGURE 1. rRNA maturation in eukaryotic cells is a multistage process with several alternative pathways, in which a primary polycistronic transcript is successively cleaved and trimmed, giving rise to normal rRNA precursors, aberrant processing intermediates, and processing by-products. (A) In human cells, $47 \mathrm{~S}$ precursor is converted to $45 \mathrm{~S}$ by primary endonucleolytic cleavages at sites $01 / \mathrm{A}^{\prime}$ and 02 (see also panel $B$ ). $45 \mathrm{~S}$ can then enter one of the three parallel pathways: The major one (represented by solid lines) involves cleavage at site 2 within ITS1, producing 30S and 32S prerRNAs. 30S species is processed to $18 \mathrm{~S}$ through 5 '-ETS and ITS1 removal. $32 \mathrm{~S}$ is cleaved at site 4, generating $12 \mathrm{~S}$ and $28.5 \mathrm{~S}$ precursors of $5.8 \mathrm{~S}$ and $28 \mathrm{~S}$ mature rRNAs. In the second pathway (represented by dashed lines), 5'-ETS is eliminated first, giving rise to $41 \mathrm{~S}$ pre-rRNA, followed by cleavage of the latter at site 2. The third pathway (represented by dotted lines) involves $41 \mathrm{~S}$ cleavage at site E in ITS1, producing 18S-E and 36S precursors. Major endonucleolytic processing events are indicated in ovals. (B) Detailed schemes of $47 \mathrm{~S}$ primary transcript (upper part), normal processing intermediates (middle part), and mature rRNAs (bottom part), presented in panel $A$. (C) Apart from regular precursors, inefficient or inaccurate pre-rRNA processing in human cells may result in the appearance of aberrant intermediates, e.g., impaired cleavage at site 01/ $A^{\prime}$ generates 30SL5 species (upper part), which is normally eliminated by XRN2 5'-3' exonuclease. Furthermore, endonucleolytic cleavages of pre-rRNAs give rise to processing by-products (bottom part). Most of them, including +1-01/A', A0-1/A1, E-2, and 4a-4 are removed by XRN2. In turn, RRP6 3'-5' exonucleolytic subunit of the exosome complex has been previously identified as a factor involved in the elimination of $01 / A^{\prime}-A 0$ species. (D) A scheme of the yeast $35 \mathrm{~S}$ primary transcript and processing by-products arising during rRNA maturation. Enzymes involved in the degradation of these intermediates are indicated. 
A

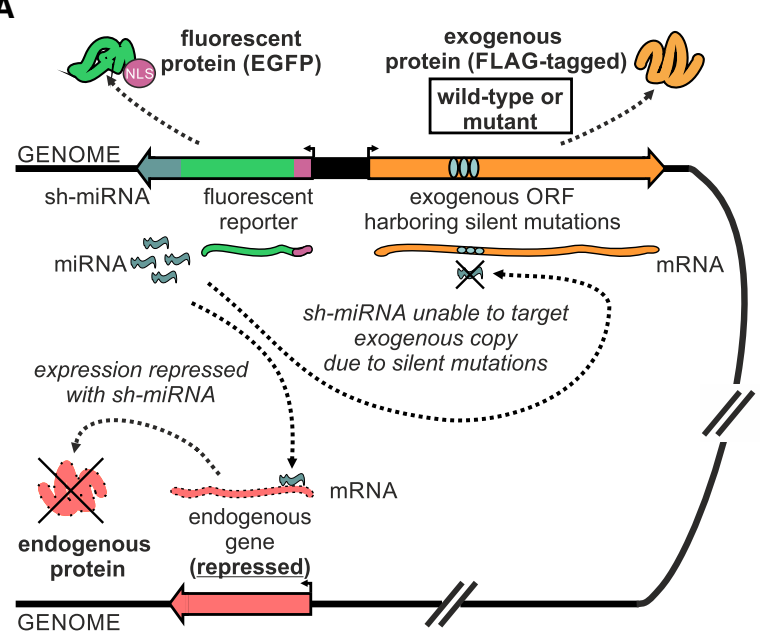

B

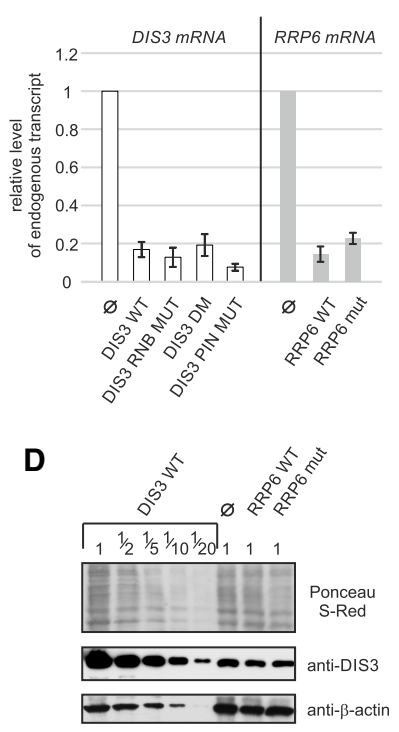

C

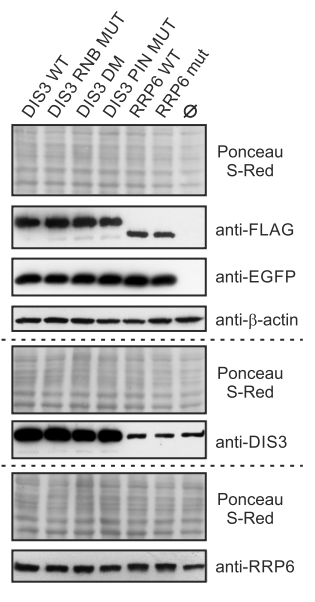

E

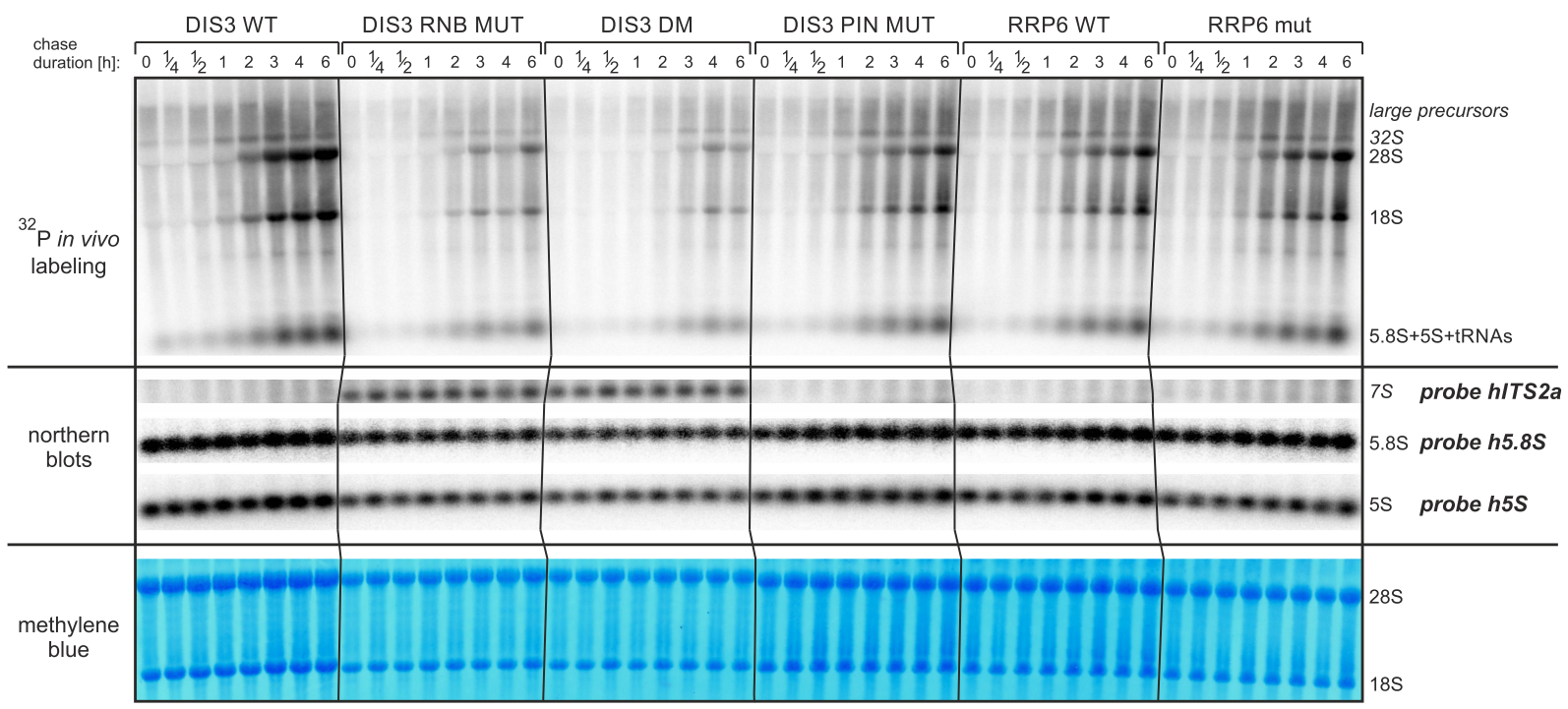

F

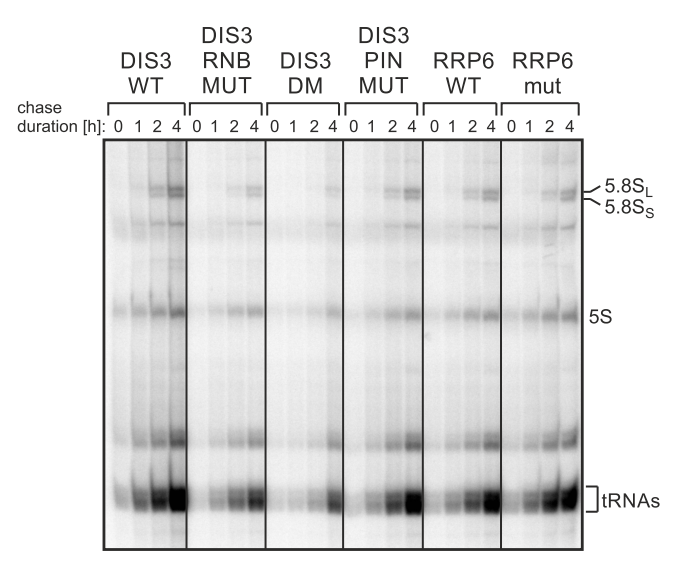

G

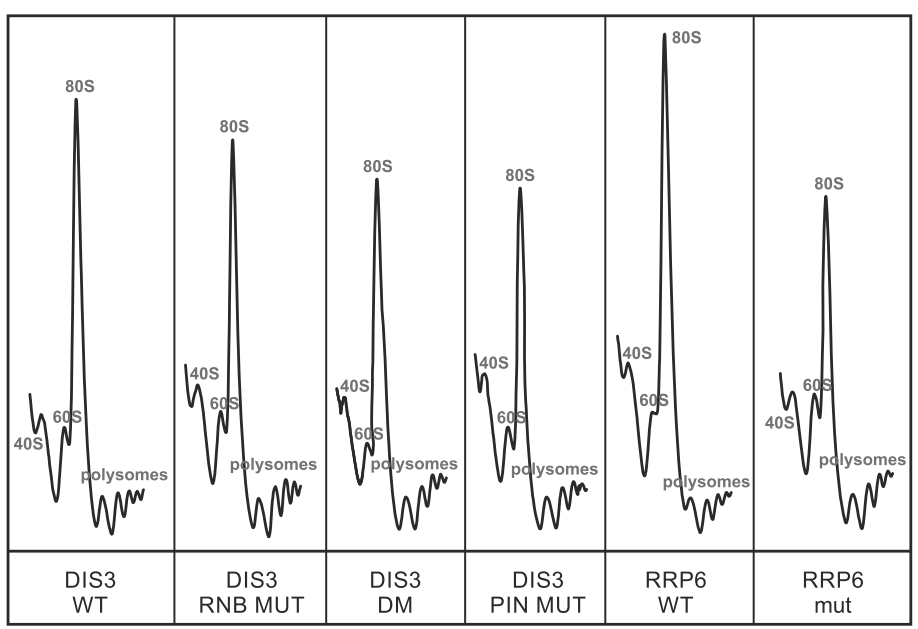

FIGURE 2. (Legend on next page) 
levels of exogenous RRP6 variants' production, in contrast to DIS3 versions (including mutant ones), which were overexpressed in model cell lines (Fig. 2C,D). Accordingly, neither cell growth nor metabolic activity of cells producing RRP6 mut variant were slowed down compared to cells expressing wild-type protein or to parental Hek293 Flp-In TREx cell line (not shown).

Next, to assess how ribosome biogenesis proceeds upon impairment of DIS3 or RRP6 enzymatic properties, model cell lines were subjected to polysome profile analysis (Fig. 2G). Results of this experiment revealed that the integrity and abundance of the 40S, 60S, 80S, and polysomes were not substantially affected in cells expressing mutant variants of either of the two exosome-associated nucleases, as compared to their wild-type counterparts. This is quite surprising for cell lines producing mutant DIS3 variants, taking into account reduced rRNA synthesis in these cells, nonetheless, it is in agreement with our previous results showing that production of ribosomal subunits/monosomes and polysome formation were not markedly disturbed in cells expressing different DIS3 mutant proteins, including those with substitutions characteristic for multiple-myeloma patients, which severely impair DIS3 exoribonucleolytic activity (see Supplemental Figure S9A therein; Tomecki et al. 2014).

In summary, we conclude that there are no significant differences in the biogenesis of ribosome particles in cell lines producing catalytically deficient nucleases associated with the RNA exosome assembly in human cells-DIS3 and RRP6, relative to their fully enzymatically active coun- terparts, despite the fact that DIS3 mutations diminish synthesis of ribosomal RNA species.

\section{Human exosome catalytic dysfunction results in strong accumulation of excised $5^{\prime}$-ETS fragments}

Experiments described in the previous section did not reveal decreased ribosome biogenesis associated with impairment of RRP6 and DIS3 catalytic activities, despite that both nucleases participate in the maturation of rRNA molecules incorporated into 60S ribosomal subunit. To more carefully inspect possible defects in pre-rRNA processing and rRNA quality control linked to exosome enzymatic dysfunctions, we performed northern blot analyses for RNA samples isolated from our model cell lines, using oligonucleotide probes complementary to different regions of 5'-ETS, ITS1, and ITS2 (see Fig. 3A for localization of the probes).

In agreement with previous reports, we observed accumulation of 7S with the probe hITS2a for cells producing DIS3 RNB MUT and DM variants, confirming that DIS3 exonucleolytically trims this precursor during $5.8 \mathrm{~S} 3$ '-end maturation (Fig. 3B). In turn, hybridizations with the probes hITS1a and hITS1b demonstrated accumulation of 21S and decreased 18S-E pre-rRNA levels in cells expressing RRP6 mut compared to RRP6 WT, corroborating prior findings on the role of RRP6 in the maturation of 18S rRNA 3'end (Fig. 3B). In addition, hybridization with probe h5ETS revealed accumulation of unknown pre-rRNA species, somewhat larger than 30S (Fig. 3B), which apparently

FIGURE 2. Expression of catalytically compromised DIS3 or RRP6 variants does not significantly affect rRNA synthesis and ribosome biogenesis in human cells. (A) General principle of the utilized cellular model. Plasmids compatible with Flp-In T-REx system from Invitrogen, containing wild-type or mutated variants of FLAG-tagged DIS3 or RRP6 and an EGFP-sh-miRNA fusion (both under the control of a bidirectional tetracycline-regulated promoter) were integrated into the Hek293 Flp-In T-REx cell line genome. The FLAG-tagged DIS3/RRP6 ORF was recoded in a way rendering it insusceptible to sh-miRNA silencing. Upon induction with tetracycline, stable cell lines produced either wild-type or mutated FLAG-tagged protein fusions and sh-miRNA silencing expression of only the respective endogenous gene. (B) sh-miRNA efficiently down-regulate expression of endogenous DIS3 and RRP6 at the mRNA level. Quantitative RT-PCR analysis was performed on total RNA isolated from Hek293 Flp-In T-REx cells $(\varnothing)$ and established model cell lines subjected to induction with tetracycline and producing either DIS3 (WT, RNB MUT, PIN MUT, or DM) or RRP6 (WT or mut) exogenous variants simultaneously with sh-miRNAs targeting respective endogenous transcript. The graph shows results of quantification of three independent experiments. GAPDH mRNA was used for normalization. The expression level is relative to the parental Hek293 Flp-In T-REx cell line. (C) Expression of exogenous DIS3 protein variants is higher than endogenous DIS3, whereas levels of exo- and endogenous RRP6 are comparable. Model cell lines (as in panel B), or parental Hek293 Flp-In T-REx cells (control), were treated with tetracycline. Proteins extracted from cells were separated in SDS-PAGE and transferred onto nitrocellulose membranes, which were stained with Ponceau S-Red and probed with antibodies specific to FLAG epitope, EGFP, DIS3, RRP6, and $\beta$-actin (loading control). (D) Exogenous DIS3 is overexpressed around five- and 10-fold compared to endogenous protein. Western blot was performed as in panel $C$, but using various dilutions of the protein sample from cell line-producing DIS3 WT variant. (E) Analysis of nascent rRNA synthesis. Model cell lines cultured in a medium containing tetracycline were pulse labeled with ${ }^{32} \mathrm{P}$ orthophosphoric acid, followed by chase in normal media for varying times (indicated above each lane). RNA was then isolated from the cells, separated in a denaturing agarose-formaldehyde gel and transferred onto nylon membrane. The blot was first stained with methylene blue (bottom part) and then subjected to phosphorimaging (upper part). Positions of $28 \mathrm{~S}$ and $18 \mathrm{~S}$ rRNA and other visible rRNA species are indicated on the right. In addition, the membrane was probed with hITS2a oligonucleotide (middle part) to monitor accumulation of 7S pre-rRNA, a known phenotype of DIS3 enzymatic dysfunction. Results of hybridizations with probes $\mathrm{h} 5.8 \mathrm{~S}$ and h5S (middle part) and staining of the membrane with methylene blue (bottom part) are shown to assess sample loading. (F) Selected samples from panel $E$ were resolved in denaturing polyacrylamide gel and subsequently subjected to phosphorimaging to visualize synthesis of small RNAs (5.8S, 5S, and tRNAs) at higher resolution. (G) Ribosome/polysome profile analysis. Native cytoplasmic extracts were prepared from model cell lines, grown in the presence of tetracycline, following translation inhibition with cycloheximide, and separated by centrifugation in linear sucrose gradients. Graphs show distribution of absorbance at $254 \mathrm{~nm}$ from the top (left) to the bottom (right). Peaks corresponding to individual subunits ( $40 \mathrm{~S}$ and $60 \mathrm{~S})$, monosomes $(80 \mathrm{~S})$, and polysomes are indicated. 
A

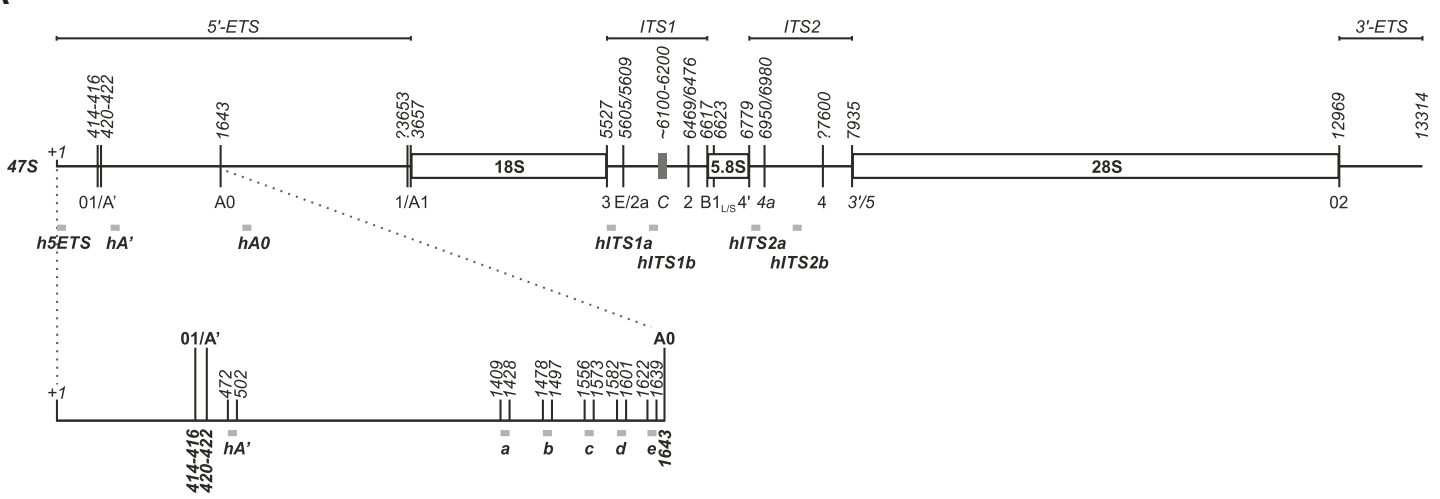

B

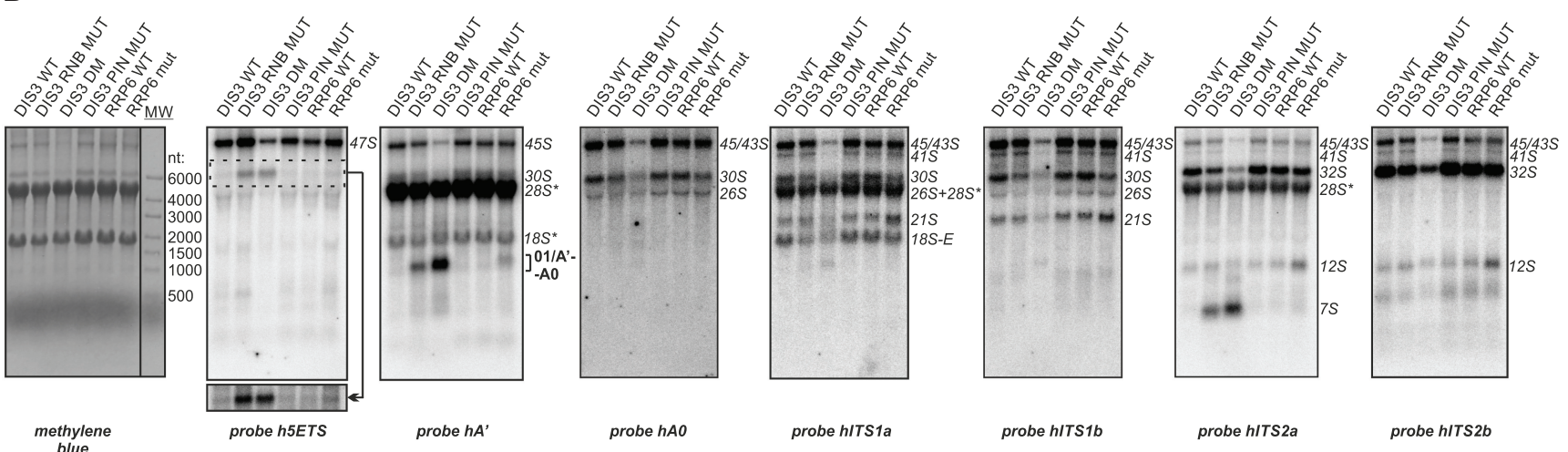

C

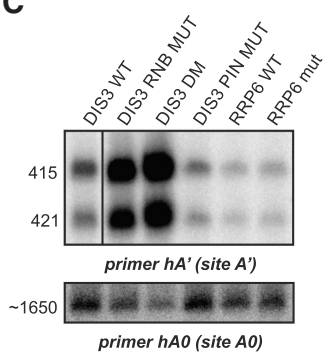

D
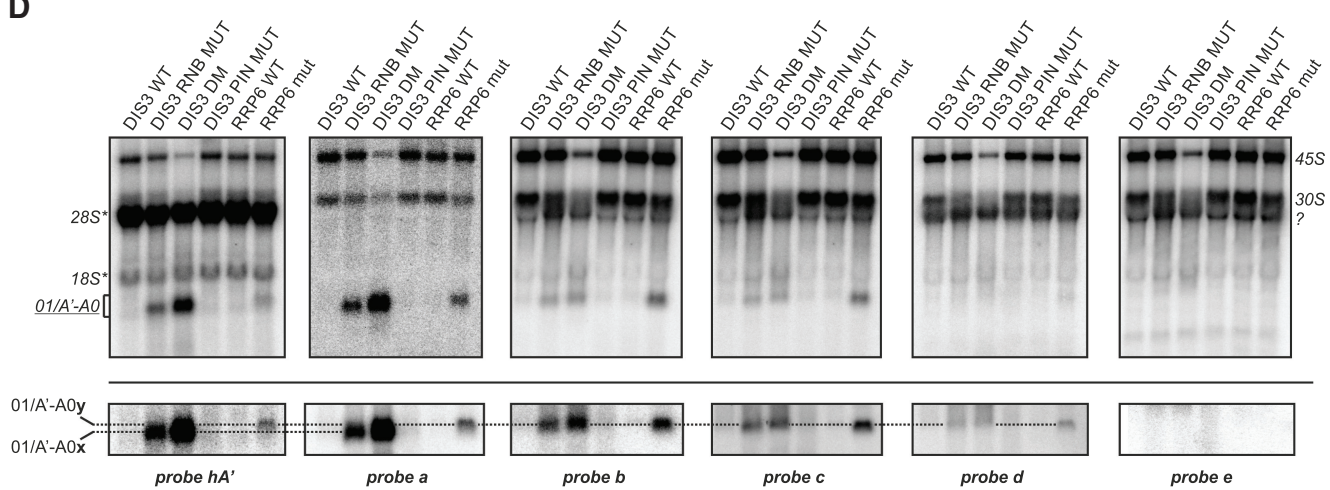

$\mathbf{E}$

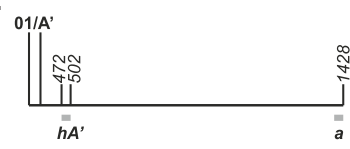

01/A'-A0x

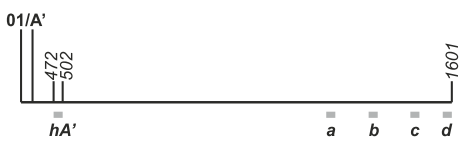

$01 / A^{\prime}-A 0 y$

FIGURE 3. Truncated $01 / A^{\prime}-A 0$ species derived from $5^{\prime}$-ETS accumulate in human cells producing enzymatically deficient exosome-associated nucleases. (A) A scheme of the human 47S pre-rRNA (top) and enlarged portion of $5^{\prime}$-ETS extending from the nucleotide +1 to the processing site $\mathrm{AO}$ (bottom). Positions of the processing sites within the $47 \mathrm{~S}$ precursor are indicated with vertical thin lines together with the names. Nucleotide numbering is according to GenBank (accession number U13369.1). Gray bars below the primary transcript show positions of northern blot probes and oligonucleotides used for primer extension in this study. (B) Northern blot analysis of pre-rRNA processing across the entire 47S precursor. Total RNA was isolated from model cell lines grown in the presence of tetracycline, separated in a denaturing agarose-formaldehyde gel, and transferred onto nylon membrane, which was then stained with methylene blue and sequentially hybridized with probes targeting various regions of 5'-ETS, ITS1, or ITS2, as indicated at the bottom. Positions of different RNA species are indicated on the right. For the probe h5ETS, the overexposed part of the membrane is additionally shown to better visualize accumulation of the long processing intermediate of unknown origin, containing +1-01/A' part of the $5^{\prime}$-ETS. (C) Primer extension analysis of pre-rRNA processing at sites 01/A' and A0 for the same RNA samples as in panel $B$. (D) Northern blot analysis of the $5^{\prime}$-ETS degradation intermediates with probes $h A^{\prime}$ and a-e, complementary to sequences located at the $5^{\prime}$-end or at a varying distance from the $3^{\prime}$-end of the excised $01 / A^{\prime}-A 0$ processing by-product. The experiment was performed as in panel B. Upper and bottom parts of the panel show results of two independent experimental replicates. The former one represents analysis for the same RNA samples as in panels $B$ and $C$. In the latter case, smaller RNA species were better separated, revealing length differences between major degradation intermediates detected by probes $h A^{\prime}$ and $a$ in comparison to probes $b-d$, which are marked with dashed lines and referred to on the left as 01/A'-A0x and 01/A'-A0y, respectively. (E) Schematic representation of the 01/A'-A0x and 01/A'-A0y decay intermediates. 
contains +1-01/A' fragment, but we have not investigated this phenomenon further. However, none of these two known phenotypes was so striking as previously overlooked accumulation of short RNA species derived from $5^{\prime}$-ETS, detectable with a probe $h A^{\prime}$ (01/A'-A0 fragment), in cells with catalytically nonfunctional DIS3. This phenomenon was observed already when the exonucleolytic activity of DIS3 was impaired in RNB MUT, but significantly enhanced upon additional inactivation of the PIN domain endonuclease in DM (Fig. 3B), indicating that both enzymatic activities of DIS3 contribute to removal of this excised 5 -ETS fragment in wild-type cells. Mutation in the active site of RRP6 resulted in a similar, albeit much milder phenotype (Fig. 3B), demonstrating that RRP6 is also involved in the degradation of this RNA species. Primer extension analyses performed with oligonucleotides hybridizing upstream sites $01 / \mathrm{A}^{\prime}$ and $\mathrm{A} 0$ demonstrated that endonucleolytic cleavages at these sites occur normally (Fig. 3C). Notably, in the case of the experiment with oligonucleotide $h A^{\prime}$, markedly increased signals were obtained for samples corresponding to cells producing DIS3 RNB MUT and DM (Fig. 3C), which corroborated northern blot data for the probe $h A^{\prime}$, demonstrating accumulation of 01/A'-A0 processing by-product.

\section{Slightly different by-products of the $5^{\prime}$-ETS degradation accumulate in cells producing catalytically inactive RRP6 or DIS3}

Despite low resolution of the northern blot results, it appeared that 5'-ETS fragments accumulating upon enzymatic dysfunction of DIS3 or RRP6 are not exactly the same size. The more pronounced band detectable with probe $h A^{\prime}$ visible in Figure 3B in lanes representing samples DIS3 RNB MUT and DIS3 DM seemed to migrate somewhat faster than the less intense band present in the lane corresponding to sample RRP6 mut. Rough estimation of the length of these $5^{\prime}$-ETS fragments suggested that it is approximately 1000-1100 nt (Fig. 3B). In turn, a signal corresponding to the full-length excised 01/A'-A0 fragment should be localized above $1200 \mathrm{nt}$ (see Fig. 3A). Taking into account that the $h A^{\prime}$ probe hybridizes to the sequence located $\sim 50$ 80 nt downstream from cleavage site $01 / A^{\prime}$, this indicated that the two accumulating RNA species represent 01/A'$A 0$ processing by-products that are truncated (referred to herein as 01/A'-A0x and 01/A'-A0y, for fragments accumulating upon impairment of enzymatic DIS3 or RRP6 functions, respectively) at one or both termini. To investigate the possibility that the truncations affect the 3 '-end of the 01/A'-A0 fragment, additional northern blot experiments were performed, using five consecutive probes (a-e) complementary to sequences between positions 1409 and 1639 of the 47S pre-rRNA (see close-up in Fig. 3A for localization of these probes), the last of which (e) annealed immediately upstream of processing site $\mathrm{A} 0$. Hybridization with probe e did not produce a signal that would correspond to the band detected previously with the probe $h A^{\prime}$, indicating that the $3^{\prime}$-ends of both $01 / A^{\prime}-A 0 x$ and 01/A'-A0y fragments are located upstream of position 1622 (Fig. 3D). Analyses performed using probes $d, c$, and $b$ demonstrated appearance of some 3 '-truncated 01/A'-A0 species in samples corresponding to cells expressing catalytically deficient DIS3 and RRP6. Since migration of this RNA is similar for samples DIS3 RNB MUT, DIS3 DM and RRP6 mut, we conclude that this band most likely represents 01/A'-A0y fragment (Fig. 3D; position indicated with dotted line in the bottom panel). Considering that the signal detectable with probe $d$ is much weaker than for probes $c$ and, particularly, $b$, we could infer that this band may in fact correspond to a series of heterogeneous processing by-products, terminating at the $3^{\prime}$ side between positions 1478-1601, with shorter 3' extensions predominating over longer ones. Importantly, hybridization with probe a revealed massive accumulation of shorter RNA species in cells producing malfunctional DIS3 (in particular the DM variant), but not RRP6 (Fig. 3D). Furthermore, results of northern blots carried out using probes $h A^{\prime}$ and $a$ were virtually identical (Fig. 3D).

Collectively, these observations suggest that the most initial degradation stage of $01 / \mathrm{A}^{\prime}-\mathrm{A} 0$ fragment excised from the 5'-ETS, i.e., removal of nucleotides 1643-1601, is controlled by some yet-unidentified nuclease, since no full-length 01/A'-A0 species could be detected upon depletion of either DIS3 or RRP6. Then, presumably both RRP6 and DIS3 participate in the decay of 01/A'-A0y processing intermediates, elongated at the $3^{\prime}$-end up to the position 1601 (Fig. 3E, right). Interfering with DIS3 enzymatic activities leads mainly to impaired degradation of 01/A'-A0x fragments, extending at the $3^{\prime}$-terminus up to position 1428, but not beyond position 1478, indicating that in wild-type cells the ultimate stage of decay is catalyzed by DIS3 (Fig. 3E, left).

\section{$5^{\prime}$-ends of 01/A'-A0 fragments coincide with 01/A' processing site, indicating the $5^{\prime}-3^{\prime}$ exonuclease is not involved in their elimination in human cells}

To further characterize RNA species derived from 01/A'-A0 5'-ETS fragment, cRT-PCR analysis was performed with a set of primers positioned as depicted in Fig. 4A for RNA samples isolated from cells producing DIS3 WT or DM and RRP6 WT or mut proteins. Specifically, we aimed at simultaneously inspecting the $5^{\prime}$ and $3^{\prime}$ termini of these RNA molecules in more detail. Results of this experiment are summarized in Fig. 4B. While the number of clones analyzed was insufficient to make qualitative comparisons between samples representing different cell lines, each of the 22 inserts sequenced corresponded to 01/A'-A0-derived fragments, which were truncated at the $3^{\prime}$-end to various extents (positions ranging from 1534 to 1634; more 
A

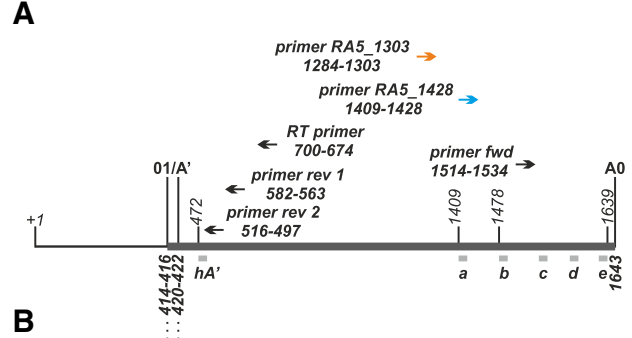

B

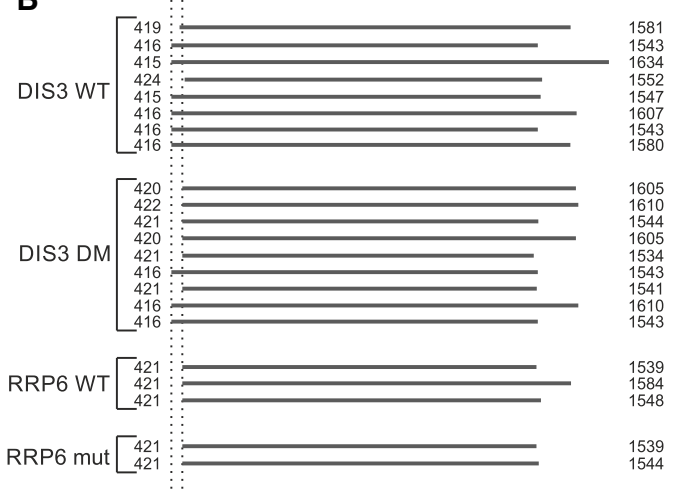

C

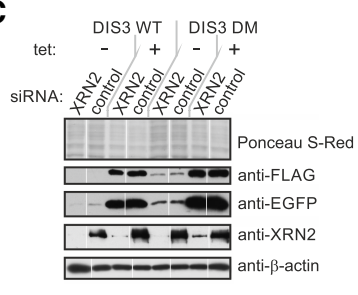

D

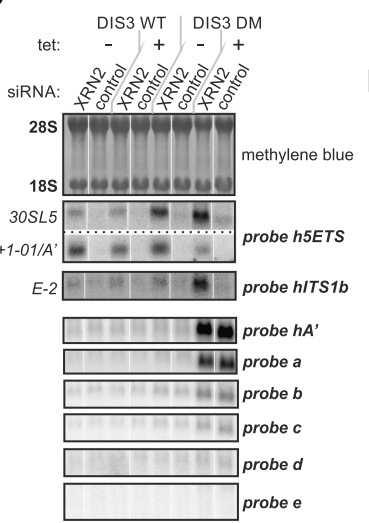

E

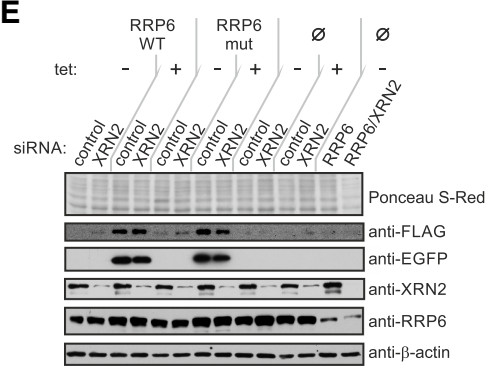

$\mathbf{F}$

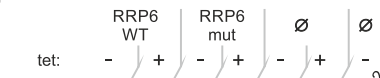

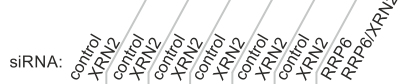

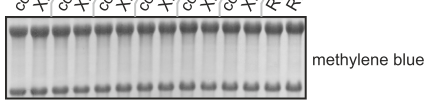

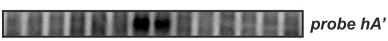

G

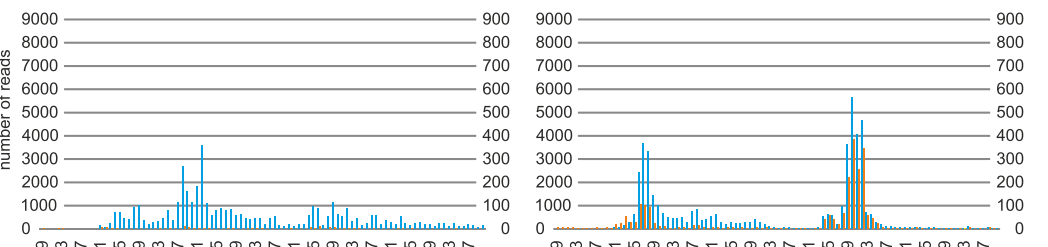

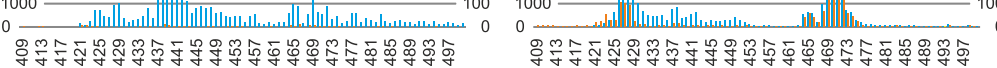

position of 3 '-end in pre-rRNA

DIS3 WT

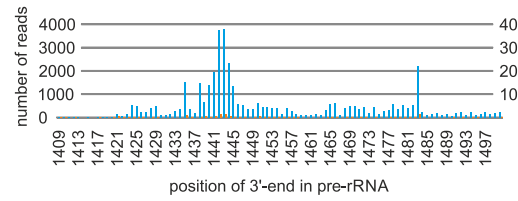

DIS3 PIN MUT position of 3 '-end in pre-rRNA

DIS3 RNB MUT

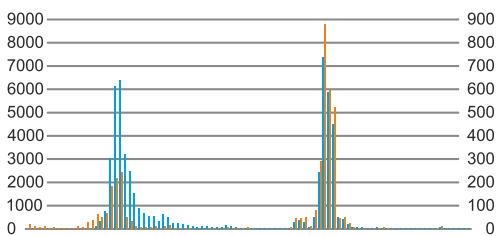

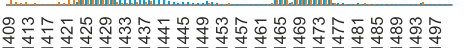

position of 3 -end in pre-rRNA

DIS3 DM

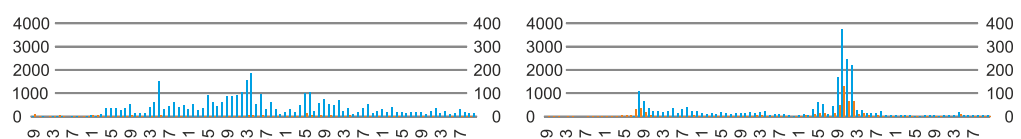

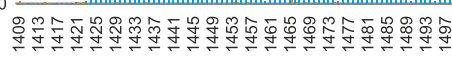

position of 3 '-end in pre-rRNA

RRP6 WT

$\mathbf{H}$

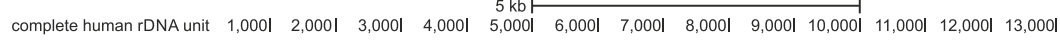

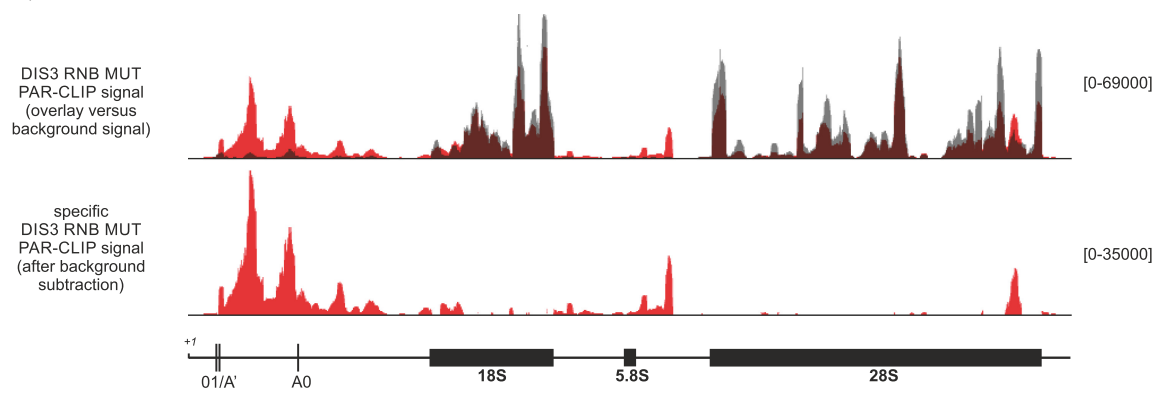

I

\begin{tabular}{|c|c|c|c|}
\hline$\underline{W T}$ & 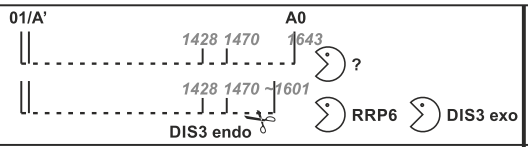 & 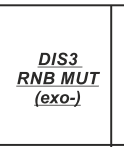 & 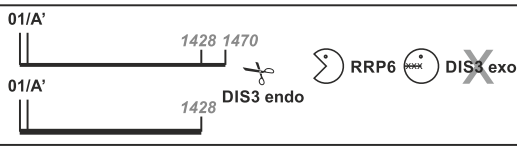 \\
\hline RRP6 mut & 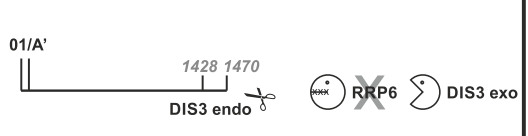 & $\begin{array}{c}\frac{D I S 3}{D M} \\
\text { (exo-, endo-) }\end{array}$ & 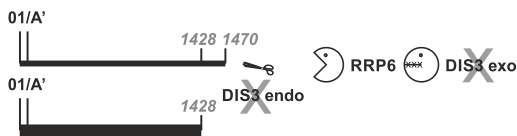 \\
\hline
\end{tabular}

FIGURE 4. (Legend on next page) 
significantly 3 '-shortened species were not detected due to the location of the forward primer utilized in CRT-PCR), while their $5^{\prime}$ terminus was intact (Fig. 4B). Since $A^{\prime}$ cleavage is known to take place at two adjacent sites: 414-416 and 420-422, some heterogeneity at the $5^{\prime}$-end was observed-molecules terminating at positions 415, 416, 419, 420, 421, and 422 were identified (Fig. 4B). Only one insert corresponded to $01 / A^{\prime}-A 0$ fragment with $5^{\prime}$ end at position 424, i.e., truncated by $2 \mathrm{nt}$, but this might be due to imperfect processing rather than the result of exonucleolytic trimming after cleavage from the primary rRNA precursor. Together with the northern blot data, CRT-PCR results suggest that the $01 / A^{\prime}-A 0$ processing by-product is rapidly digested in the $3^{\prime}-5^{\prime}$ direction with the participation of two exosome-associated nucleases: RRP6 and DIS3, acting in a collaborative manner. Moreover, we see no indication for the involvement of $5^{\prime}-$ 3 ' nuclear exoribonucleases, such as XRN2, in elimination of this RNA species in human cells, although it was previously suggested by other authors (Sloan et al. 2014).

To further analyze the contribution of $3^{\prime}-5^{\prime}$ and $5^{\prime}-3^{\prime}$ exonucleolytic pathways in the degradation of excised 01/A'A0 species, siRNA-mediated down-regulation of XRN2 expression in cells producing the DIS3 DM protein variant was performed. Western blot experiments confirmed efficient reduction in the levels of XRN2 protein (Fig. 4C). In addition, pre-rRNA processing dysfunctions characteristic to XRN2 depletion, such as accumulation of 30SL5, +1-01/ $A^{\prime}$ and E-2 species, were demonstrated (Fig. 4D). Nonetheless, XRN2 silencing did not exert an additive effect on the levels of truncated 01/A'-A0 by-product in the background of DIS3 DM expression (Fig. 4D). Likewise, XRN2 depletion combined with RRP6 catalytic mutation in our model cell line or with simultaneous siRNA-mediated down-regulation of RRP6 in the parental Hek293 Flp-In T-REx cell line did not lead to synergistic accumulation of the analyzed species (Fig. 4E,F).

Altogether, 01/ $\mathrm{A}^{\prime}-\mathrm{A} 0$ processing intermediates appear to be degraded exclusively by the $3^{\prime}-5^{\prime}$ nucleases, including in particular exosome-associated DIS3 and RRP6, but not by the XRN2, primarily responsible for the nuclear degradative pathway acting in the $5^{\prime}-3^{\prime}$ direction.

\section{1/A'-A0 processing by-product elimination involves the cooperative action of RRP6 and both nucleolytic activities of DIS3}

To examine 01/A'-A0 by-product exonucleolytic decay intermediates in cell lines producing different variants of DIS3 or RRP6 more globally, 3'-RACE analysis was

FIGURE 4. $01 / \mathrm{A}^{\prime}-\mathrm{A} 0$ processing by-product is degraded in human cells in the $3^{\prime}-5^{\prime}$ direction by the cooperative action of RRP6 and DIS3, but not by XRN2. (A) Location of primers (arrows) and probes (gray bars) utilized in cRT-PCR (RT, fwd, rev1, rev2), 3'-RACE-seq (RA5_1428, RA5_1303), and northern blot ( $\left.h A^{\prime}, a-e\right)$ analyses, within 01/A'-A0 fragment of the $5^{\prime}$-ETS. (B) cRT-PCR mapping of $5^{\prime}-E T S$ 01/A'-A0 decay intermediates present in model cell lines producing DIS3 WT or DM and RRP6 WT or mut proteins. Each line represents an individual sequenced insert from Topo cloning. Numbers on the left and the right indicate $5^{\prime}$ - and $3^{\prime}$-ends of the identified fragments, respectively. Vertical dotted lines show positions of the doublet 01/A' cleavage site. With one exception, the $5^{\prime}$ terminus of the $01 / A^{\prime}$ decay intermediates is intact, indicating that the $5^{\prime}-3^{\prime}$ exonuclease XRN2 is not involved in the elimination of this species. (C) Model cell lines able to produce exogenous DIS3 WT or DM variants were either untreated ("tet: -") or treated ("tet: +") with tetracycline, and transfected with siRNA against XRN2 or with control, unrelated siRNA; proteins extracted from cells were separated in SDS-PAGE and transferred onto nitrocellulose membrane, which was stained with Ponceau S-Red and then sequentially probed with antibodies specific to FLAG epitope, EGFP, XRN2, and $\beta$-actin (loading control). (D) Northern blot analysis for RNA samples isolated from model cell lines described in panel $C$. Total RNA was separated in the denaturing agarose-formaldehyde gel and transferred onto nylon membrane, which was then stained with methylene blue and sequentially hybridized with different probes, as indicated on the right. Analysis of $5^{\prime}$-ETS degradation intermediates with probes $h A^{\prime}$ and a-e showed that XRN2 silencing does not exert any additive effect on the accumulation of 01/A'-A0 decay intermediates in cells producing DIS3 DM protein variant. Probes h5ETS and hITS1b were additionally used to demonstrate phenotypes characteristic to XRN2 depletion-positions of RNA species accumulating upon XRN2 down-regulation (30SL5 aberrant precursor and +1-01/A' and E-2 processing by-products) are indicated on the left. (E) Western blot analysis was performed as in panel $C$, for protein samples isolated from model cell lines able to produce exogenous RRP6 WT or mut, as well as for parental Hek293 Flp-In T-REx cells ( $)$ ). In addition, the latter cells were subjected to RNA interference using siRNA targeting RRP6 alone or in combination with XRN2 (two rightmost lanes). (F) Northern blot analysis for RNA samples isolated from model cell lines described in panel E. XRN2 down-regulation did not exert any synergistic effect on the accumulation of truncated 01/A'-A0 5'-ETS fragment in conjunction with RRP6 catalytic mutation or siRNA-mediated depletion. (G) 3'-RACE-seq analysis of the 01/A'-A0 decay intermediates in cells producing different DIS3 and RRP6 protein variants. Blue bars and scale on the left of each graph represent the number of reads, the $3^{\prime}$-end of which mapped to a given position in pre-rRNA (indicated at the bottom) in the analysis with 3'-RACE primer RA5_1428; orange bars and scale on the right of each graph correspond to the experiment performed using 3'RACE primer RA5_1303 (see panel A for the location of 3-RACE primers). (H) Genome Browser screenshots of DIS3 PAR-CLIP data mapped to the consensus sequence of the complete human rDNA repeating unit. Each track represents the mean signal of two biological replicates. Upper part shows the overlay of DIS3 PAR-CLIP signal (red) and the background signal (gray). Lower part represents a specific signal, calculated by subtraction of the background mock signal from the PAR-CLIP signal obtained for DIS3 RNB MUT-expressing cells. Coverage signal corrected to mapped library is shown in size square parentheses on the right of each track. A simplified rRNA precursor scheme is shown at the bottom, with 01/A' and $A 0$ sites marked with vertical lines. (I) A model for exosome-mediated 01/A'-A0 by-product decay. In wild-type cells, 01/A'-A0 fragment arising after endonucleolytic cleavages is rapidly attacked first by an unknown enzyme and then by the exosome-associated nucleases, and efficiently degraded. RRP6 is mainly involved in the first phase of exosome-mediated decay, but DIS3 also contributes to this process. In turn, further efficient degradation of 01/A'-A0 species requires both catalytic activities of DIS3. Upon their impairment, RRP6 activity is insufficient to eliminate this by-product, which results in a profound accumulation of decay intermediates ending approximately at position 1428 of pre-rRNA. 
performed, followed by massive sequencing of the amplification products. In the first experiment, a forward primer RA5_1428 with the 3'-most nucleotide corresponding to position 1428 of pre-rRNA was used (see Fig. 4A for location of the 3'-RACE primers). Expression of DIS3 RNB MUT or DIS3 DM resulted in overrepresentation of reads corresponding to molecules terminating around positions $\sim 1470$ and $\sim 1428$, which was not observed for cells producing DIS3 WT or DIS3 PIN MUT (blue peaks in Fig. $4 \mathrm{G})$. Because the second set of reads, although specific to DIS3 RNB MUT and DIS3 DM samples, could be an artifact caused by positioning of the primer, additional analysis was performed with a forward primer RA5_1303, the $3^{\prime}$-end of which ended more upstream, at position 1303 (Fig. 4A). While the number of reads was an order of magnitude lower, accumulation of molecules with $3^{\prime}$ termini around positions $\sim 1470$ and $\sim 1428$ was faithfully recapitulated (orange peaks in Fig. 4G). These phenotypes were more pronounced for DIS3 DM than DIS3 RNB MUT (Fig. $4 G)$, corroborating earlier observations that both exoand endonucleolytic activity of DIS3 participate in the degradation of such RNA species in wild-type cells. A critical role of DIS3 in the decay of 01/A'-A0 fragment was additionally confirmed by re-analysis of our previous PARCLIP experiment results (Szczepińska et al. 2015), now focused on rRNA (Fig. 4H). Majority of the reads for cells producing DIS3 RNB MUT accumulated between sites $01 / A^{\prime}$ and $A 0$ compared to the mock control (nontransfected Hek293 Flp-In T-REx cells) (Fig. 4H). Much less signal has accumulated over the background levels downstream from 5.8S rRNA 3'-end, corresponding to the most physiologically important DIS3 target site in the pre-rRNA processing pathway (Fig. 4H). Notably, virtually no reads were mapped upstream of 01/ $\mathrm{A}^{\prime}$ cleavage site, which confirmed that $+1-01 / A^{\prime}$ processing by-product is entirely invulnerable to $3^{\prime}-5^{\prime}$ digestion by the exosome, and indeed removed solely by XRN2 in the opposite direction.

Expression of RRP6 mut led only to the increased number of reads representing truncated $01 / A^{\prime}-A 0$ intermediates with $3^{\prime}$-ends located around position $\sim 1470$, but not $\sim 1428$ (Fig. 4G) in the 3'-RACE-seq analysis. This complements well results of northern blot analyses and demonstrates that RRP6, apparently together with or prior to DIS3, is involved in the 01/A'-A0 fragment decay phase directly following the initial exonucleolytic stage of its degradation, presumably controlled by an enzyme unrelated to exosome (Fig. 4I). However, it is difficult to estimate the relative contribution of both exosome-associated nucleases to this process. On the contrary, $3^{\prime}-5^{\prime}$ degradation of 01/A'-A0 by-product beyond position $~ 1470$ depends mainly on synergistic action of exo- and endoribonuclease activities of DIS3 (Fig. 4I). Upon their impairment, RRP6 probably continues elimination of this species, albeit with significantly limited efficiency, resulting in an arrest around position 1428 (Fig. 4l).

\section{Conclusions}

The complexity of eukaryotic ribosomal RNA maturation requires tight cooperation between different endo- and exoribonucleases. Since the yeast and human exosome contains two nucleases-DIS3 and RRP6, responsible for three distinct enzymatic activities-their functions at various stages of pre-rRNA processing must also be precisely coordinated. The most thoroughly studied and physiologically most important processing event involving both DIS3 and RRP6 proteins is $3^{\prime}-5^{\prime}$ trimming of pre-5.8S species, eventually generating mature $5.8 \mathrm{~S}$ molecules. Analyses of rRNA precursors accumulating in vivo upon interfering with activities of exosome-associated nucleases in yeast, supported by a wealth of biochemical and structural investigations led to the conclusion that this phenomenon is initiated by Dis3, but due to structural constraints, the subsequent processing phase is taken over by Rrp6. The $5.8 \mathrm{~S}$ 3 '-end processing mechanism based on the nuclease handover, with DIS3 acting prior to RRP6, is most likely conserved in human cells (Tafforeau et al. 2013).

Another prominent yeast exosome substrate in the prerRNA processing pathway is the $5^{\prime}$-ETS degradation intermediate arising after endonucleolytic cleavage at site $A_{0}$ : +1-A $A_{0}$, known to be degraded by both activities of Dis3 and Rrp6 exonuclease (Lebreton et al. 2008). Nonetheless, its detailed decay mechanism, compared to $5.8 \mathrm{~S} 3^{\prime}$-end processing, still remains elusive. An additional recently identified layer of the regulation of this process involves transition of the $+1-A_{0}$ RNA species delivery route to the exoribonuclease active site of Dis3 (Delan-Forino et al. 2017b). The degradation stage controlled by Dis3 exonucleolytic activity comprises two phases, of which the initial one is based on the substrate threading via the exosome complex central channel (Delan-Forino et al. 2017b). Then, because of steric occlusion due to the presumable secondary structure in the $+1-A_{0}$ decay intermediate, the $3^{\prime}$-end of the RNA substrate is extruded from the channel and delivered to Dis3 exonuclease via direct access path (Makino et al. 2015; Han and van Hoof 2016; Zinder et al. 2016; Delan-Forino et al. 2017a,b).

An interplay between DIS3 and RRP6 activities is also a hallmark of 5'-ETS elimination during ribosome biogenesis in Arabidopsis thaliana (Chekanova et al. 2007; Lange et al. 2008, 2011; Kumakura et al. 2013; Sikorski et al. 2015). Furthermore, a recent study demonstrated that contrary to yeast and humans, the exosome core subunit RRP41 in plants (and possibly some nonplant lower eukaryotes) has retained a distributive phosphorolytic activity, which also considerably contributes to this process (Sikorska et al. 2017). More specifically, northern blot and high-resolution 3'-RACE-seq mapping of 5'-ETS decay intermediates 3'ends in $A$. thaliana revealed that some by-products of $P$ $P^{\prime}$ fragment, which can be considered as a counterpart of the yeast $+1-A_{0}$ and human $01 / A^{\prime}-A 0$ species, are 
preferentially trimmed by the intrinsic core activity of the complex, which probably enables handing them over to DIS3 and RRP6 nucleases for further degradation (Sikorska et al. 2017).

The data presented herein expand our knowledge about the $5^{\prime}$-ETS elimination mechanism in human cells. We show that the $01 / A^{\prime}-A 0$ fragment is not a substrate for $5^{\prime}-3^{\prime}$ exonuclease activity of XRN2. Instead, after initial trimming by a yet-unidentified enzyme its decay is mediated by the exosome-associated nucleases: RRP6 and DIS3. Importantly, the nuclease handover beginning with RRP6 and followed by DIS3 is not illegitimate from the structural viewpoint (Makino et al. 2015). Hence, our functional studies indicate that the human $01 / A^{\prime}-A 0$ species might represent the first identified exosome substrate, which follows such a degradation pathway, which is in sharp contrast to 5.8S rRNA 3'end maturation, where initial DIS3-mediated trimming is followed by RRP6 and eventually completed by exosomeindependent distributive RNases (Tomecki et al. 2017).

Experimental data acquainted from various model organisms clearly indicate that the coordinated involvement of multiple nucleolytic exosome activities is a common feature of the $5^{\prime}$-ETS removal during pre-rRNA processing across the eukaryotic kingdom. Nonetheless, the molecular details of this phenomenon vary between taxa. This is both due to some variations in the exosome complex enzymatic properties and significant divergence of $5^{\prime}$-ETS at the sequence and/or secondary structure levels, which dictates different requirements for particular nucleases at individual stages of $5^{\prime}$-ETS elimination in yeast, plant, and human cells.

\section{MATERIALS AND METHODS}

\section{Cell cultures}

Stable human cell lines derived previously (Tomecki et al. 2014; Szczepińska et al. 2015) from Hek293 Flp-In T-REx cells (Invitrogen) were cultured as monolayers in Dulbecco's modified Eagle's medium (DMEM, Gibco) supplemented with $10 \%$ fetal bovine serum (FBS, Gibco) and antibiotics (penicillin-streptomycin, P/S; Sigma-Aldrich) at $37^{\circ} \mathrm{C}$ in a $5 \% \mathrm{CO}_{2}$ humidified atmosphere. Expression of sh-miRNA-EGFP cassettes for silencing of the endogenous genes and sh-miRNA-insensitive FLAG-tagged exogenous DIS3 or RRP6 protein variants was induced by addition of tetracycline to the culture medium at a final concentration of $25 \mathrm{ng} / \mathrm{mL}$. Cells were grown for $48 \mathrm{~h}$ before harvesting.

\section{Polysome profile analysis}

Cytoplasmic extracts for polysome profile analysis were prepared as follows. Stable cell lines were grown in the presence of tetracycline on two $\varnothing 145 \mathrm{~mm}$ dishes until reaching $~ 90 \%$ confluence. Cells were treated with cycloheximide $(100 \mu \mathrm{g} / \mathrm{mL})$ at $37^{\circ} \mathrm{C}$ for $5 \mathrm{~min}$. The medium was then aspired and the cells were gently washed with ice-cold PBS containing $100 \mu \mathrm{g} / \mathrm{mL}$ cycloheximide.
After thorough removal of PBS, the dishes were transferred on ice and in-dish lysis was performed using $700 \mu \mathrm{L}$ of lysis buffer (20 mM Tris- $\mathrm{HCl}, \mathrm{pH}=7.4 ; 100 \mathrm{mM} \mathrm{KCl} ; 5 \mathrm{mM} \mathrm{MgCl} 2 ; 2 \mathrm{mM}$ DTT; $100 \mu \mathrm{g} / \mathrm{mL}$ cycloheximide; $1 \%$ Triton X-100, reduced [Sigma-Aldrich]; 1× Protease Inhibitor Cocktail, cOmplete EDTA-free [Roche]; $100 \mathrm{U} / \mathrm{mL}$ SUPERase*In RNase inhibitor [Ambion]). Lysed cells were scraped off the dishes with the use of a rubber policeman, triturated six times through a 26-gauge needle, and the lysates were then clarified by centrifugation at $15,000 \mathrm{~g}$ for $15 \mathrm{~min}$ at $4^{\circ} \mathrm{C}$. RNA concentration in cytoplasmic extracts was measured using Nanodrop 2000c spectrophotometer (Thermo Scientific). Fifteen $\mathrm{OD}_{260}$ units of extracts in $500 \mu \mathrm{L}$ of lysis buffer were layered onto $10 \%-50 \%(w / v)$ sucrose gradients, prepared using filtered sucrose solutions in a polysome buffer (20 mM HEPES-KOH, pH 7.4; 100 mM KCl; 5 mM MgCl $; 2$ mM DTT; $100 \mu \mathrm{g} / \mathrm{mL}$ cycloheximide; $1 \times$ Protease Inhibitor Cocktail, cOmplete EDTA-free), and ultracentrifuged at 36,000 rpm for 3 $\mathrm{h}$ at $4^{\circ} \mathrm{C}$ in $\mathrm{TH}-641$ rotor (Sorvall). Subsequently, $0.5 \mathrm{~mL}$ fractions were collected from the gradient by pumping $60 \%$ sucrose solution in the polysome buffer to the bottom of tubes, and $\mathrm{OD}_{260}$ was monitored on ÄKTA Purifier.

\section{RNA isolation and northern blot analyses}

RNA was isolated from human Hek293 Flp-In T-REx-derived cell lines using TRI reagent (Sigma-Aldrich) according to manufacturer's instructions. Five micrograms of total RNA was separated by electrophoresis in a $1 \%$ formaldehyde-agarose gel prepared using TT buffer (30 mM tricine; $30 \mathrm{mM}$ triethanolamine, $\mathrm{pH}=8.0$ ), followed by RNA immobilization on the Hybond $\mathrm{N}^{+}$membrane (Amersham) by overnight capillary transfer in $20 \times$ SSC (3 M $\mathrm{NaCl} ; 0.3 \mathrm{M}$ sodium citrate). RNA was fixed by UV-crosslinking and the membrane was stained with methylene blue $(0.03 \%$ solution in $0.3 \mathrm{M}$ sodium acetate, $\mathrm{pH}=5.3$ ). Hybridizations were performed in PerfectHyb Plus hybridization buffer (Sigma-Aldrich). The blots were handled according to standard procedures and probed with 5'-labeled DNA oligonucleotides (sequences listed in Supplemental Table S1) at $42^{\circ} \mathrm{C}$ overnight. After each hybridization, membranes were washed twice for 30 min with $2 \times$ SSC, $0.1 \%$ SDS at $42^{\circ} \mathrm{C}$, and eventually exposed to a Phosphorlmager screen (FujiFilm), which was scanned using a FLA 7000 scanner (FujiFilm). Between successive hybridizations, probes were stripped off the membranes at $65^{\circ} \mathrm{C}$ using boiling $0.1 \%$ SDS.

\section{Quantitative RT-PCR}

Ten micrograms of total RNA was treated with $6 U$ of TURBO DNase (Ambion) in the presence of RiboLock RNase Inhibitor (Thermo Scientific), according to the manufacturer's instructions. Following phenol:chloroform extraction and precipitation of RNA with isopropanol, $2 \mu \mathrm{g}$ of DNase-treated RNA was reverse transcribed using a mixture of 50 pmol of an oligo(dT) 18 primer and $250 \mathrm{ng}$ of random hexamers (Invitrogen) and Superscript III reverse transcriptase (Invitrogen), according to the manufacturer's instructions, in a final volume of $20 \mu \mathrm{L}$. A portion (1/100) of the cDNA reaction was mixed with Platinum Quantitative PCR SuperMix-UDG (Invitrogen), 2.5 pmol of each primer (Supplemental Table S1) and $0.3 \mu \mathrm{g}$ of bovine serum albumin in a final volume of $10 \mu \mathrm{L}$ and analyzed by real-time PCR in a Roche LightCycler 480 
system using an annealing temperature of $58^{\circ} \mathrm{C}$. Analyses were performed in triplicate and data were normalized to GAPDH mRNA.

\section{Metabolic labeling of nascent RNA}

Stable Hek293 Flp-In T-REx-derived cell lines were grown on $\varnothing 60$ $\mathrm{mm}$ dishes in a standard DMEM containing tetracycline until reaching $\sim 80 \%$ confluence. The cells were then preincubated for 60 min in DMEM without phosphates (Gibco), supplemented with $10 \%$ dialyzed FBS (Sigma-Aldrich) and P/S. Subsequently, [ ${ }^{32} \mathrm{P}$ ]orthophosphoric acid $(0.1 \mathrm{mCi} / \mathrm{mL}$; Hartmann Analytic) was added to the medium, and the dishes were incubated with isotope for $60 \mathrm{~min}$ before changing the medium for a standard DMEM. Cells were harvested in PBS following Trypsin-EDTA (Sigma-Aldrich) digestion and collected by centrifugation at the following time-points after final medium change: $0.5,1,1.5,2$, and $4 \mathrm{~h}$. Total RNA was extracted as described above and resolved in 1\% agarose-formaldehyde gel in TT buffer. RNA was then transferred onto Hybond $\mathrm{N}^{+}$membrane (Amersham) and the results were analyzed by phosphorimaging. For analysis of smaller transcripts, RNA was resolved in 10\% denaturing polyacrylamide gel with $8 \mathrm{M}$ urea, which was then directly exposed to a Phosphorlmager screen.

\section{Primer extension analysis}

DNA oligonucleotides for primer extension were labeled with T4 PNK (NEB) and $2 \mu \mathrm{L}\left[\gamma^{32}{ }^{32} \mathrm{P}\right] \mathrm{ATP}$ (Hartmann Analytic; $3000 \mathrm{Ci}$ / $\mathrm{mmol}$ ) in a total volume of $10 \mu \mathrm{L}$, according to the instructions of the enzyme's manufacturer. Reaction was terminated at $90^{\circ} \mathrm{C}$ for $5 \mathrm{~min}$. Labeled DNA was diluted to $50 \mu \mathrm{L}$ with sterile deionized water and extracted once with an equal volume of phenol:chloroform (1:1). Upper phase was transferred to a new tube and DNA was precipitated with $500 \mu \mathrm{L}$ of isopropanol in the presence of $5 \mu \mathrm{L}$ of $3 \mathrm{M}$ sodium acetate $(\mathrm{pH}=5.2)$ and $1 \mu \mathrm{L}$ of RNase-free glycogen $(20 \mathrm{mg} / \mathrm{mL})$. Following wash with $80 \%$ ethanol and air-drying, DNA pellet was dissolved in $20 \mu \mathrm{L}$ of RNase-free water.

Four micrograms of total RNA was mixed with $2 \mu \mathrm{L}$ of $5^{\prime}$-labeled DNA oligo and $2 \mu \mathrm{L}$ of $5 \times$ ssHyb buffer $(50 \mathrm{mM}$ Tris- $\mathrm{HCl}, \mathrm{pH}=7.5$; $1.5 \mathrm{M} \mathrm{NaCl}$; $10 \mathrm{mM}$ EDTA, $\mathrm{pH}=8.0$ ) in a total volume of $10 \mu \mathrm{L}$. The mixture was incubated at $85^{\circ} \mathrm{C}$ for $7 \mathrm{~min}$ and then the thermoblock was set to $42^{\circ} \mathrm{C}$ to allow annealing of the primer to RNA. In the meantime, a master mix containing $26.75 \mu \mathrm{L}$ of RNase-free water, $6.25 \mu \mathrm{L}$ of $10 \times$ AMV RT buffer (NEB), $5 \mu \mathrm{L}$ of $10 \mathrm{mM}$ dNTP (dATP, dGTP, dCTP, dTTP) Mix, $1 \mu \mathrm{L}$ of RiboLock RNase Inhibitor (40 U/ $\mu \mathrm{L}$; Thermo Scientific), and $1 \mu \mathrm{L}$ of AMV Reverse Transcriptase (NEB) per sample, was prepared and pre-warmed at $42^{\circ} \mathrm{C}$. After annealing, $40 \mu \mathrm{L}$ of the master mix was added to the sample and the incubation was carried out at $42^{\circ} \mathrm{C}$ for 90 min. Reaction was stopped at $95^{\circ} \mathrm{C}$ for $5 \mathrm{~min}$ and the products were subjected to single extraction with an equal volume of phenol:chloroform (1:1). DNA was precipitated, washed, dried, and dissolved as described above. Subsequently, $20 \mu \mathrm{L}$ of formamide loading dye ( $90 \%$ formamide in $1 \times$ TBE, $0.03 \%$ xylene cyanol, $0.03 \%$ bromophenol blue) were added and primer extension products were analyzed by electrophoresis in $6 \%$ denaturing polyacrylamide-urea gels $(0.4 \mathrm{~mm}$ thick). Following electrophoretic separation, the gel was transferred onto Whatman $3 \mathrm{MM}$ filter paper, covered with saran wrap, and dried for 90 min at $70^{\circ} \mathrm{C}$ under vacuum. The gel was exposed to a Phosphorlmager screen, which was subsequently scanned using a FLA 7000 scanner.

\section{RNA interference}

For siRNA-mediated XRN2 or RRP6 gene silencing, the model cell lines derived from Hek293 Flp-In T-REx cells or parental cells were grown to $30 \%-40 \%$ confluence, either in the absence or in the presence of doxycycline, and subjected to Stealth siRNA (Invitrogen; respective IDs: HSS176944 and HSS182420) transfection. Scrambled Stealth RNAi siRNA duplex (Invitrogen, cat. no. 12935200) was used as a negative control. Transfections were performed in $\varnothing 100 \mathrm{~mm}$ culture dishes using Lipofectamine RNAiMAX (Invitrogen) and 20 nM siRNA according to the manufacturer's recommendations.

\section{Western blotting}

Protein samples from human cell lines were prepared according to standard protocols, resolved in 10\%-12\% SDS-PAGE gels, and immobilized on Protran nitrocellulose membranes (Whatman) by electrotransfer using Trans-Blot SD Semi-Dry Transfer Cell (Bio-Rad). Following transfer, membranes were stained with Ponceau S Red (Sigma-Aldrich; $0.1 \%$ in 3\% acetic acid), blocked in 5\% nonfat milk in TBS containing $0.05 \%$ Tween-20 (TBST), and incubated in the same solution with primary antibodies. The following primary antibodies were used for analyses: rabbit polyclonal antiFLAG (Sigma-Aldrich; F7425 or Proteintech; 20543-1-AP), mouse monoclonal anti-EGFP (B2) (Santa Cruz Biotechnology; sc-9996), mouse monoclonal anti-XRN2 (H-3) (Santa Cruz Biotechnology; sc-365258), and mouse monoclonal anti- $\beta$-actin (Sigma-Aldrich; A5441). Membranes were then washed with TBST and incubated with appropriate secondary antibody (goat anti-rabbit, goat antimouse [Calbiochem; 401393, 401215, respectively]) conjugated with horseradish peroxidase. Blots were developed in a Curix 60 machine (AGFA) using the Immun-Star WesternC Kit (BioRad) and CL-XPosure Films (Thermo Scientific).

\section{CRT-PCR}

Ten micrograms of total RNA was subjected to circularization with 10 units of T4 RNA ligase I in a volume of $10 \mu \mathrm{L}$ at $16^{\circ} \mathrm{C}$ overnight. The resulting circular RNA was subjected to standard phenolchloroform extraction, precipitated with isopropanol and resuspended in $7 \mu \mathrm{L}$ of water. Subsequently, $3 \mu \mathrm{L}$ of RT primer ( 5 $\mathrm{pmol} / \mu \mathrm{L}$ ) were added and annealed by heating the sample in the PCR machine at $75^{\circ} \mathrm{C}$ for $5 \mathrm{~min}$, followed by incubation at $37^{\circ} \mathrm{C}$ for $30 \mathrm{~min}$ and at $25^{\circ} \mathrm{C}$ for $15 \mathrm{~min}$. Then, $4 \mu \mathrm{L}$ of $5 \times$ SuperScript III First-Strand Buffer (Thermo Scientific), $1 \mu \mathrm{L}$ dNTP Mix (dATP, dGTP, dCTP, dUTP; $10 \mathrm{mM}$ each), $20 \mathrm{U}$ of RiboLock RNase Inhibitor, $2 \mu \mathrm{L} 0.1 \mathrm{M} \mathrm{DTT}$, and water to $19 \mu \mathrm{L}$, were added. The reaction mixture was heated at $42^{\circ} \mathrm{C}$ for $2 \mathrm{~min}$ and reverse transcription was performed by addition of $200 \mathrm{U} / \mu \mathrm{L}$ of SuperScript III Reverse Transcriptase (Thermo Scientific) and incubation at $42^{\circ} \mathrm{C}$ for $60 \mathrm{~min}$, followed by enzyme inactivation at $70^{\circ}$ $\mathrm{C}$ for $15 \mathrm{~min}$. The first-strand CDNA (10 $\mu \mathrm{L}$ of the above reaction mixture) was subjected to PCR with primer fwd and primer rev 
1. One microliter of the first-round PCR product was used as template in the second PCR round with primer fwd-primer rev 2. Both rounds of amplification were carried out using Phusion DNA polymerase with Phusion HF Buffer (Thermo Scientific) according to the manufacturer's instructions. The following PCR profile was utilized: initial denaturation at $98^{\circ} \mathrm{C}$ for $5 \mathrm{~min}, 35$ cycles of amplification (with denaturation at $98^{\circ} \mathrm{C}$, annealing at $55^{\circ} \mathrm{C}$ and elongation at $72^{\circ} \mathrm{C}$ carried out for 30,30 , and $60 \mathrm{sec}$, respectively), and final elongation at $72^{\circ} \mathrm{C}$ for $10 \mathrm{~min}$. The final PCR products were cloned with the use of Zero Blunt Topo PCR Cloning Kit (Invitrogen), and the inserts were sequenced using M13 Forward (-20) and M13 Reverse oligonucleotides, following recommendations of the manufacturer.

\section{3'-RACE-seq}

High-throughput analysis of the RNA 3'-ends was performed essentially as described previously (Kobylecki et al. 2017), with some modifications listed hereafter, using $2 \mu \mathrm{g}$ of total RNA as a starting material. Following RA3 adapter ligation and reverse transcription with RTP primer, two-step amplification was performed for high-throughput sequencing of the $3^{\prime}$-RACE products. The first-round PCR reaction mixture contained $20 \mu \mathrm{L}$ of the firststrand cDNA, $0.2 \mathrm{mM}$ dNTP Mix, $20 \mu \mathrm{M}$ primer pair RA5_1428/ 1303-RPI_X (with Illumina index for RNA-seq), 5x Phusion HF Buffer, Phusion DNA polymerase, and sterile water to $40 \mu \mathrm{L}$. The following PCR profile was utilized: initial denaturation at $98^{\circ} \mathrm{C}$ for $30 \mathrm{sec}, 10$ cycles of amplification (with denaturation at $98^{\circ} \mathrm{C}$, annealing at $55^{\circ} \mathrm{C}$ and elongation at $72^{\circ} \mathrm{C}$ carried out for 10,30 , and $30 \mathrm{sec}$, respectively), and final elongation at $72^{\circ} \mathrm{C}$ for $5 \mathrm{~min}$. The second-round PCR reaction mixture comprised $10 \mu \mathrm{L}$ of the first-round PCR products, $0.2 \mathrm{mM}$ dNTP Mix, $20 \mu \mathrm{M}$ primer pair RP1-RPI_X, 5× Phusion HF Buffer, Phusion DNA polymerase, and sterile water to $50 \mu \mathrm{L}$. PCR profile was the same as above, but with only five cycles of amplification. The resulting 3'-RACE-seq libraries were purified and sequenced using an Illumina NextSeq 500 System as described elsewhere (Kobylecki et al. 2017).

\section{PAR-CLIP data analysis}

Previously published PAR-CLIP data for Hek293 Flp-In T-REx cell line producing a DIS3 RNB MUT-EGFP fusion protein as well as for parental, nontransfected control cells (Szczepińska et al. 2015) have been re-analyzed in an approach targeted at rRNA. Data sets in duplicates have been aligned using STAR short read aligner to human ribosomal DNA consensus sequence, with the use of custom-prepared indexes containing the complete ribosomal DNA repeating unit (GenBank accession: U13369.1), 5S rRNA (accession: NR_023363.1), and mitochondrial 12S rRNA (RNR1) (accession: NR_137294.1), as well as 16S rRNA (RNR2) (accession: NR_137295.1), which have been treated as control sequences. On average, $0.5 \mathrm{M}$ reads of the DIS3 RNB MUT PAR-CLIP and $0.75 \mathrm{M}$ reads of the mock control mapped uniquely to the ribosomal sequence, which constituted $7 \%$ and $16 \%$ of the total library size, respectively. Custom scripts incorporating elements of the wiggleTools package were used to subtract the background from the PAR-CLIP signal and to prepare the tracks, which were eventually visualized using the UCSC genome browser soft- ware. The final results were analyzed using the feature annotation of a complete rDNA repeating unit provided by GenBank.

\section{SUPPLEMENTAL MATERIAL}

Supplemental material is available for this article.

\section{ACKNOWLEDGMENTS}

This work was supported by grants from the National Centre for Research and Development (NCBR LIDER/35/46/L-3/11/NCBR/ 2012) and the Polish National Science Centre (UMO-2011/01/ D/NZ1/03510) to R.T. Additional financial support was provided by the TEAM program of the Foundation for Polish Science, cofinanced by the European Union via the European Regional Development Fund (agreement no. TEAM/2016-1/3). Experiments were carried out with the use of CePT infrastructure, which was financed by the European Union via the European Regional Development Fund (Innovative Economy 2007-13, agreement no. POIG.02.02.00-14-024/08-00). K.D. was supported by a grant from the Polish National Science Centre (UMO-2015/16/S/NZ1/ 00086). We acknowledge Paweł S. Krawczyk for his assistance with 3'-RACE-seq and data analysis.

Author contributions: K.K. carried out primer extension assays, performed CRT-PCR and 3'-RACE-seq analyses under the supervision of R.T., and participated in RNA metabolic labeling and northern blot experiments. K.D. performed preliminary northern blot analyses. T.M.K. analyzed PAR-CLIP data. A.D. participated in the design of experiments and data interpretation. R.T. conceived and directed the studies, performed polysome profile analyses, RNA metabolic labeling, majority of hybridizations and immunoblotting, and wrote the manuscript, with contributions from K.D. and A.D.

Received May 10, 2018; accepted September 17, 2018.

\section{REFERENCES}

Allmang C, Kufel J, Chanfreau G, Mitchell P, Petfalski E, Tollervey D. 1999. Functions of the exosome in rRNA, snoRNA and snRNA synthesis. EMBO J 18: 5399-5410.

Allmang C, Mitchell P, Petfalski E, Tollervey D. 2000. Degradation of ribosomal RNA precursors by the exosome. Nucleic Acids Res 28: 1684-1691.

Bonneau F, Basquin J, Ebert J, Lorentzen E, Conti E. 2009. The yeast exosome functions as a macromolecular cage to channel RNA substrates for degradation. Cell 139: 547-559.

Briggs MW, Burkard KT, Butler JS. 1998. Rrp6p, the yeast homologue of the human PM-Scl 100-kDa autoantigen, is essential for efficient 5.8 S rRNA 3' end formation. J Biol Chem 273: 13255-13263.

Burkard KT, Butler JS. 2000. A nuclear $3^{\prime}-5^{\prime}$ exonuclease involved in mRNA degradation interacts with poly(A) polymerase and the hnRNA protein Npl3p. Mol Cell Biol 20: 604-616.

Chekanova JA, Gregory BD, Reverdatto SV, Chen H, Kumar R, Hooker T, Yazaki J, Li P, Skiba N, Peng Q, et al. 2007. Genomewide high-resolution mapping of exosome substrates reveals hidden features in the Arabidopsis transcriptome. Cell 131: 13401353.

Delan-Forino C, Schneider C, Tollervey D. 2017a. RNA substrate length as an indicator of exosome interactions in vivo. Wellcome Open Res 2: 34 
Delan-Forino C, Schneider C, Tollervey D. 2017b. Transcriptomewide analysis of alternative routes for RNA substrates into the exosome complex. PLoS Genet 13: e1006699.

Drazkowska K, Tomecki R, Stodus K, Kowalska K, CzarnockiCieciura M, Dziembowski A. 2013. The RNA exosome complex central channel controls both exonuclease and endonuclease Dis3 activities in vivo and in vitro. Nucleic Acids Res 41: 3845-3858.

Dziembowski A, Lorentzen E, Conti E, Séraphin B. 2007. A single subunit, Dis3, is essentially responsible for yeast exosome core activity. Nat Struct Mol Biol 14: 15-22.

Fromm L, Falk S, Flemming D, Schuller JM, Thoms M, Conti E, Hurt E. 2017. Reconstitution of the complete pathway of ITS2 processing at the pre-ribosome. Nat Commun 8: 1787.

Han J, van Hoof A. 2016. The RNA exosome channeling and direct access conformations have distinct in vivo functions. Cell Rep 16: 3348-3358.

Henry Y, Wood H, Morrissey JP, Petfalski E, Kearsey S, Tollervey D. 1994. The $5^{\prime}$ end of yeast 5.8S rRNA is generated by exonucleases from an upstream cleavage site. EMBO J 13: 2452-2463.

Kent T, Lapik YR, Pestov DG. 2009. The 5' external transcribed spacer in mouse ribosomal RNA contains two cleavage sites. RNA 15: 14-20.

Kilchert C, Wittmann S, Vasiljeva L. 2016. The regulation and functions of the nuclear RNA exosome complex. Nat Rev Mol Cell Biol 17: 227-239.

Kobylecki K, Kuchta K, Dziembowski A, Ginalski K, Tomecki R. 2017. Biochemical and structural bioinformatics studies of fungal CutA nucleotidyltransferases explain their unusual specificity toward CTP and increased tendency for cytidine incorporation at the $3^{\prime}-$ terminal positions of synthesized tails. RNA 23: 1902-1926.

Kumakura N, Otsuki H, Tsuzuki M, Takeda A, Watanabe Y. 2013. Arabidopsis AtRRP44A is the functional homolog of Rrp44/Dis3, an exosome component, is essential for viability and is required for RNA processing and degradation. PLoS One 8: e79219.

Łabno A, Tomecki R, Dziembowski A. 2016a. Cytoplasmic RNA decay pathways-enzymes and mechanisms. Biochim Biophys Acta 1863: 3125-3147.

Łabno A, Warkocki Z, Kuliński T, Krawczyk PS, Bijata K, Tomecki R, Dziembowski A. 2016b. Perlman syndrome nuclease DIS3L2 controls cytoplasmic non-coding RNAs and provides surveillance pathway for maturing snRNAs. Nucleic Acids Res 44: 1043710453.

Lange $\mathrm{H}$, Holec S, Cognat V, Pieuchot L, Le Ret M, Canaday J, Gagliardi D. 2008. Degradation of a polyadenylated rRNA maturation by-product involves one of the three RRP6-like proteins in Arabidopsis thaliana. Mol Cell Biol 28: 3038-3044.

Lange H, Sement FM, Gagliardi D. 2011. MTR4, a putative RNA helicase and exosome co-factor, is required for proper rRNA biogenesis and development in Arabidopsis thaliana. Plant J 68: 51-63.

Lebreton A, Tomecki R, Dziembowski A, Séraphin B. 2008. Endonucleolytic RNA cleavage by a eukaryotic exosome. Nature 456: 993-996.

Lykke-Andersen S, Tomecki R, Jensen TH, Dziembowski A. 2011. The eukaryotic RNA exosome: same scaffold but variable catalytic subunits. RNA Biol 8: 61-66.

Makino DL, Baumgärtner M, Conti E. 2013. Crystal structure of an RNA-bound 11-subunit eukaryotic exosome complex. Nature 495: 70-75.

Makino DL, Schuch B, Stegmann E, Baumgärtner M, Basquin C, Conti E. 2015. RNA degradation paths in a 12-subunit nuclear exosome complex. Nature 524: 54-58.

Malet H, Topf M, Clare DK, Ebert J, Bonneau F, Basquin J, Drazkowska K, Tomecki R, Dziembowski A, Conti E, et al. 2010.
RNA channelling by the eukaryotic exosome. EMBO Rep 11: 936-942.

Memet I, Doebele C, Sloan KE, Bohnsack MT. 2017. The G-patch protein NF-KB-repressing factor mediates the recruitment of the exonuclease XRN2 and activation of the RNA helicase DHX15 in human ribosome biogenesis. Nucleic Acids Res 45: 5359-5374.

Mitchell P, Petfalski E, Tollervey D. 1996. The $3^{\prime}$ end of yeast $5.8 \mathrm{~S}$ rRNA is generated by an exonuclease processing mechanism. Genes Dev 10: 502-513.

Mitchell P, Petfalski E, Shevchenko A, Mann M, Tollervey D. 1997. The exosome: a conserved eukaryotic RNA processing complex containing multiple $3^{\prime} \rightarrow 5^{\prime}$ exoribonucleases. Cell 91: 457-466.

Petfalski E, Dandekar T, Henry Y, Tollervey D. 1998. Processing of the precursors to small nucleolar RNAs and rRNAs requires common components. Mol Cell Biol 18: 1181-1189.

Preti M, O'Donohue MF, Montel-Lehry N, Bortolin-Cavaillé ML, Choesmel V, Gleizes PE. 2013. Gradual processing of the ITS1 from the nucleolus to the cytoplasm during synthesis of the human 18S rRNA. Nucleic Acids Res 41: 4709-4723.

Schaeffer D, Tsanova B, Barbas A, Reis FP, Dastidar EG, SanchezRotunno M, Arraiano CM, van Hoof A. 2009. The exosome contains domains with specific endoribonuclease, exoribonuclease and cytoplasmic mRNA decay activities. Nat Struct Mol Biol 16: $56-62$.

Schneider C, Leung E, Brown J, Tollervey D. 2009. The N-terminal PIN domain of the exosome subunit Rrp44 harbors endonuclease activity and tethers Rrp44 to the yeast core exosome. Nucleic Acids Res 37: 1127-1140.

Schuller JM, Falk S, Fromm L, Hurt E, Conti E. 2018. Structure of the nuclear exosome captured on a maturing preribosome. Science 360: 219-222.

Sikorska N, Zuber H, Gobert A, Lange H, Gagliardi D. 2017. RNA degradation by the plant RNA exosome involves both phosphorolytic and hydrolytic activities. Nat Commun 8: 2162.

Sikorski PJ, Zuber H, Philippe L, Sement FM, Canaday J, Kufel J, Gagliardi D, Lange H. 2015. Distinct $18 S$ rRNA precursors are targets of the exosome complex, the exoribonuclease RRP6L2 and the terminal nucleotidyltransferase TRL in Arabidopsis thaliana. Plant J 83: 991-1004.

Sloan KE, Mattijssen S, Lebaron S, Tollervey D, Pruijn GJ, Watkins NJ. 2013. Both endonucleolytic and exonucleolytic cleavage mediate ITS1 removal during human ribosomal RNA processing. J Cell Biol 200: 577-588.

Sloan KE, Bohnsack MT, Schneider C, Watkins NJ. 2014. The roles of SSU processome components and surveillance factors in the initial processing of human ribosomal RNA. RNA 20: 540-550.

Szczepińska T, Kalisiak K, Tomecki R, Labno A, Borowski LS, Kulinski TM, Adamska D, Kosinska J, Dziembowski A. 2015. DIS3 shapes the RNA polymerase II transcriptome in humans by degrading a variety of unwanted transcripts. Genome Res 25: 1622-1633.

Tafforeau L, Zorbas C, Langhendries JL, Mullineux ST, Stamatopoulou V, Mullier R, Wacheul L, Lafontaine DL. 2013. The complexity of human ribosome biogenesis revealed by systematic nucleolar screening of pre-rRNA processing factors. Mol Cell 51: 539-551.

Tomecki R, Kristiansen MS, Lykke-Andersen S, Chlebowski A, Larsen KM, Szczesny RJ, Drazkowska K, Pastula A, Andersen JS, Stepien PP, et al. 2010. The human core exosome interacts with differentially localized processive RNases: hDIS3 and hDIS3L. EMBO J 29: 2342-2357.

Tomecki R, Drazkowska K, Kucinski I, Stodus K, Szczesny RJ, Gruchota J, Owczarek EP, Kalisiak K, Dziembowski A. 2014. Multiple myeloma-associated hDIS3 mutations cause perturbations in cellular RNA metabolism and suggest hDIS3 PIN domain as a potential drug target. Nucleic Acids Res 42: 1270-1290. 


\section{Kobyłecki et al.}

Tomecki R, Labno A, Drazkowska K, Cysewski D, Dziembowski A. 2015. hUTP24 is essential for processing of the human rRNA precursor at site A1, but not at site A0. RNA Biol 12: 1010-1029.

Tomecki R, Sikorski PJ, Zakrzewska-Placzek M. 2017. Comparison of preribosomal RNA processing pathways in yeast, plant and human cells-focus on coordinated action of endo- and exoribonucleases. FEBS Lett 591: 1801-1850.

Wang M, Pestov DG. 2011. 5'-end surveillance by Xrn2 acts as a shared mechanism for mammalian pre-rRNA maturation and decay. Nucleic Acids Res 39: 1811-1822.
Wasmuth EV, Lima CD. 2012. Exo- and endoribonucleolytic activities of yeast cytoplasmic and nuclear RNA exosomes are dependent on the noncatalytic core and central channel. Mol Cell 48: 133144.

Zinder JC, Lima CD. 2017. Targeting RNA for processing or destruction by the eukaryotic RNA exosome and its cofactors. Genes Dev 31: 88-100.

Zinder JC, Wasmuth EV, Lima CD. 2016. Nuclear RNA exosome at 3.1 $\AA$ reveals substrate specificities, RNA paths, and allosteric inhibition of Rrp44/Dis3. Mol Cell 64: 734-745. 

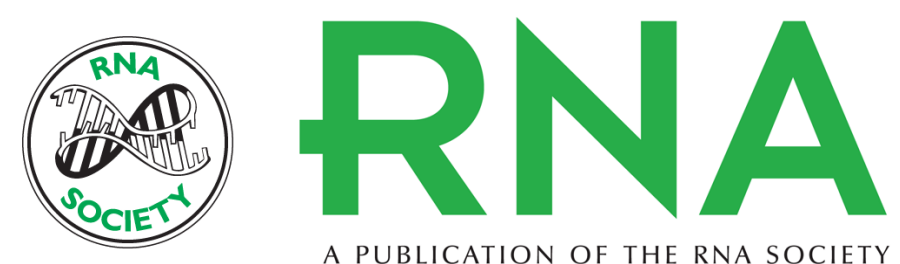

A PUBLICATION OF THE RNA SOCIETY

\section{Elimination of $01 / \mathbf{A}^{\prime}-\mathbf{A} 0$ pre-rRNA processing by-product in human cells involves cooperative action of two nuclear exosome-associated nucleases: RRP6 and DIS3}

Kamil Kobylecki, Karolina Drazkowska, Tomasz M. Kulinski, et al.

RNA 2018 24: 1677-1692 originally published online September 28, 2018

Access the most recent version at doi:10.1261/rna.066589.118

Supplemental Material

References

Creative Commons License

Email Alerting Service
http://rnajournal.cshlp.org/content/suppl/2018/09/27/rna.066589.118.DC1

This article cites 48 articles, 15 of which can be accessed free at: http://rnajournal.cshlp.org/content/24/12/1677.full.html\#ref-list-1

This article is distributed exclusively by the RNA Society for the first 12 months after the full-issue publication date (see http://rnajournal.cshlp.org/site/misc/terms.xhtml). After 12 months, it is available under a Creative Commons License (Attribution-NonCommercial 4.0 International), as described at http://creativecommons.org/licenses/by-nc/4.0/.

Receive free email alerts when new articles cite this article - sign up in the box at the top right corner of the article or click here.

\section{|||||||| Providing Precise Solutions for} your research.

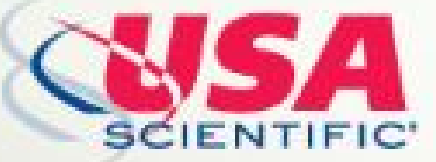

To subscribe to RNA go to:

http://rnajournal.cshlp.org/subscriptions

(C) 2018 Kobylecki et al.; Published by Cold Spring Harbor Laboratory Press for the RNA Society 